Audsley,E.; Pearn,K.R.; Harrison,P.A.; Berry,P.M. The impact of future socio-economic and climate changes on agricultural land use and the wider environment in East Anglia and North West England using a metamodel system. Clim.Change, 2008, 90, 1-2, 57-88

\title{
The impact of future socio-economic and climate changes on agricultural land use and the wider environment in East Anglia and North West England using a metamodel system.
}

\author{
E.Audsley $^{1}{ }^{\bowtie}$, K.R.Pearn ${ }^{1}$, P.A Harrison ${ }^{2}$ and P.M. Berry ${ }^{2}$ \\ ${ }^{1}$ Silsoe Research Institute, Wrest Park, Silsoe, Bedford MK45 4HS, UK. \\ ${ }^{2}$ Environmental Change Institute, Oxford University Centre for the Environment, South Parks Road, \\ Oxford, OX1 3QY, UK. \\ Corresponding author: \\ E.Audsley \\ Cranfield University \\ Cranfield \\ Bedford MK43 0AL \\ United Kingdom
}

Tel: $\quad+44(0) 1234750111$

Email: e.audsley@cranfield.ac.uk

This paper describes a procedure to use a model interactively to investigate future land use by studying a wide range of scenarios defining climate, technological and socio-economic changes. A full model run of several hours has been replaced by a metamodel version which takes a few seconds, and provides the user with an immediate visual output and with the ability to examine easily which factors have the greatest effect. The Regional Impact Simulator combines a model of agricultural land use choices linked with models of urban growth, flooding risk, water quality and consequences for wildlife to estimate plausible futures of agricultural land on a timescale of 20-50 years. The model examines the East Anglian and North West regions of the United Kingdom at a grid resolution of $5 \mathrm{x}$ $5 \mathrm{~km}$, and for each scenario estimates the most likely cropping and its profitability at each location, and classifies land use as arable, intensive or extensive grassland or abandoned. From a modelling viewpoint the metamodel approach enables iteration. It is thus possible to determine how product prices change so that production meets demand. The results of the study show that in East Anglia cropping remains quite stable over a wide range of scenarios, though grassland is eliminated in scenarios with the 2050s High climate scenario - almost certainly due to the low yield in the drier conditions. In the North West there is a very much greater range of outcomes, though all scenarios suggest a reduction in grassland with the greatest in the 2050s High climate scenario combined with the "Regional Stewardship" (environmental) socio-economic scenario. The effects of the predicted changes in land use on plant species showed suitability for species to vary greatly, particularly between the socio-economic scenarios, due to detrimental effects from increases in nitrogen fertilisation. A complete simulation with the Regional Impact Simulator takes around 20 seconds (computer-dependent), which users who responded felt was adequate or better than adequate. The main areas for future improvement, such as the speed of the system, user interaction and the accuracy and detail of the modelling, are considered.

\section{Introduction}

Agriculture constitutes 8.7Mha of the 12.5Mha of land in England and is thus the major use of land in spite of the huge growth of urbanisation (Defra, 2004). 3.7Mha is permanent grass, of which $0.7 \mathrm{Mha}$ is rough grazing. The remaining $5 \mathrm{Mha}$ is arable cropping, of which typically $0.7 \mathrm{Mha}$ is temporary grass. It is evident that farmers' choices are driven by prices, subsidies, costs and crop yields, and the results of changes in these parameters over time can be seen in the census data, with increasing areas 
of winter wheat in the east and forage maize in the west, with consequential effects on the use of herbicides, fertiliser and irrigation. Consequences are observed both in the short term (choice of crop) and in the long term (grassland or arable farming).

Changes in cropping patterns and practices have led to a reduction in the extent of cereal field margins, a Biological Action Plan (BAP, 1995) priority habitat which is important for wildlife. There is increasing evidence that the addition of fertilisers, most notably nitrogen, in such habitats has a major influence on plant species composition, through affecting nutrient availability and productivity (Marshall et al., 2001). Galium aparine (cleavers), for example, flourishes in the high fertility sites associated with cereal farming (Grime et al., 1988). The distribution of this species has increased from a 21\% coverage in central England in the 1960s to 88\% in 1997 (Sutcliffe and Kay, 2000). Alternatively, nitrogen application can be detrimental to arable species which are less competitive (Wilson and King, 2003). The decline of many arable weeds over the last 50 years has been partly attributed to the increased use of fertilisers (Preston et al., 2002). Scandix pectin veneris (shepherd's needle), for example, has declined in abundance from the mid 1950s (Stewart et al., 1994). Experiments in Hampshire showed how a modern winter wheat variety fertilised at a level typical of farming practice can reduce the numbers of uncommon arable plant species, with $S$. pectin veneris decreasing from 7.1 plants per $\mathrm{m}^{2}$ with no nitrogen fertiliser application to 4.4 per $\mathrm{m}^{2}$ with half the amount used in normal practice to 3 per $\mathrm{m}^{2}$ with standard nitrogen inputs (Wilson and King, 2003). This would support the concerns of Parmesan and Yohe (2003) that over the short-term, land use change will be an important driver of local biological changes and this will increase species' vulnerability. Berry et al. (2006) also have shown how changes in agriculture could affect species' vulnerability under different climate and socio-economic scenarios.

The use of models to analyse climate and socio-economic scenarios has become a common way of studying likely future consequences of changes, whether they are due to technology, policy, climate or consumers. Audsley et al. (2006) and Rounsevell et al. (2003) describe a two-step procedure to estimate future agricultural land use. Firstly, future crop yields are estimated, and then based on these values the cropping which optimises the farm's profitability is estimated. The spatial analysis is based on identifying the climate and all the significant soil types within a $5 \times 5 \mathrm{~km}$ grid and analysing each soil-climate combination. This is a more spatially detailed analysis than that of Hossell et al. (1996) who use typical regional farms, but has the disadvantage that the analysis is very computer-intensive and thus time-consuming. Similar ideas have been developed by Koomen et al. (2005) to predict future agriculture in Holland, and Munier (2004) in Denmark where the objective was the impact on ecology and the environment. Zander and Kachele (1999) also sought to combine a crop and farm model but using a crop model based on expert knowledge. This has the advantage of including disease effects which the soil moisture model of Rounsevell et al. (2003) cannot do, but has the potential disadvantage of it being very difficult to systematically calculate future crop yields for a wide range of circumstances, without including calculations equivalent to the soil moisture model. Cellular automata, in which changes in the state of a cell (e.g. agriculture to housing) depends also on the state of its adjacent cells, are a common way to carry out spatially explicit analyses of land use (de Nijs, 2004). These are of most value where the use of land is very much a function of the neighbouring use such as with the spread of urban land. In agriculture, similarity between neighbours mainly occurs due to similar soil and climate conditions. Changes in land use are more strongly related to changes in the relative profitability between options. Thus it is most important to analyse the options in each cell, and ignore changes to its neighbouring cells.

Holman et al. (2005a \& b) describe a spatial analysis of two regions in England which integrates an analysis of urban development, flood risk, water flow, water quality and ecological impact with the agricultural land use analysis, using very detailed models. However, because of this, the models are time-consuming and the number of situations that can be analysed is very limited. The use of scenarios is an attempt to get round the problem of there being a large number of input parameters which define a situation. Although some may be correlated, there are still an extremely large number of significantly different valid combinations of parameters which are not studied. In practice it means that it is difficult to know which changes are actually responsible for the effects observed. Holman et al. (2005a and b) studied the effects of climate and economics separately and showed that economics 
has more effect than climate, but it would be useful to be able to separate the effects within these - is the climate effect due to winter or summer rainfall, or the economic effect due to yields or costs? However a detailed analysis of the influence of the many different socio-economic scenario data such as prices, costs and yield changes was effectively impossible because of the long run times of such detailed models. The same applies to studying the influence of changes in temperature and rainfall in the climate scenarios on the results. Clearly time required is a function of many things, not least the specification of the computer, but even at one hundredth of a second per year, given 30 years of weather, 12 crops and 1226 grids in East Anglia and the North West each with on average 4 soils, the elapsed time for one set of crop yield input data is nearly 5 hours. The farm model which is a substantial linear programme, simulates 10 farms on each soil in each grid which at one tenth of a second per farm is of the order of 2 hours.

Replacing the detailed models by metamodels and applying them to representative grids provides a solution. Metamodels are reduced models which endeavour to capture the major systematic effects shown in the full models. Metamodels which carry out an equivalent analysis in the order of a second, enable both a detailed spatial analysis and analysis of the effects of different input parameters. They also enable other features to be introduced such as iteratively adjusting prices based on supply and demand and restricting irrigation. Their obvious disadvantage is that they lose some of the detailed and systematic effects of the full models. It may be that the average total response is correct, but it could equally be systematically high or low. Responses at extremes are most likely to suffer, partly because of the form of the models and partly because there will be less original data to influence the fitting of the metamodel. Thus from the infinite set of possible metamodels, it is possible to make good and bad choices, and even with careful choice, there is certain to exist a better one.

This paper describes the development of a procedure using metamodels, to investigate interactively, spatially explicit future land use given future scenarios, and to relate the resulting distribution of arable land and nitrogen fertiliser use, to the suitability for species in cereal field margin habitats within East Anglia and North West England. Figure 1 shows the location of the study regions in England. As in Holman et al. (2005a), the method is still based on identifying the climate and all the significant soil types within a $5 \times 5 \mathrm{~km}$ grid and analysing each soil-climate combination. The scenarios define the changes in climate, technology and socio-economics which influence the choices made by farmers, and hence are a major determinant of the ecology and the environment in England. However unlike traditional scenario modelling, the user is free to change most of the input parameters and thus investigate an infinite number of scenarios and study the responses of the system to parameters of their choice. The target is to run one complete integrated analysis in less than one second, though at present this has not quite been achieved, with 10-20 seconds being typical run-times for one scenario analysis.

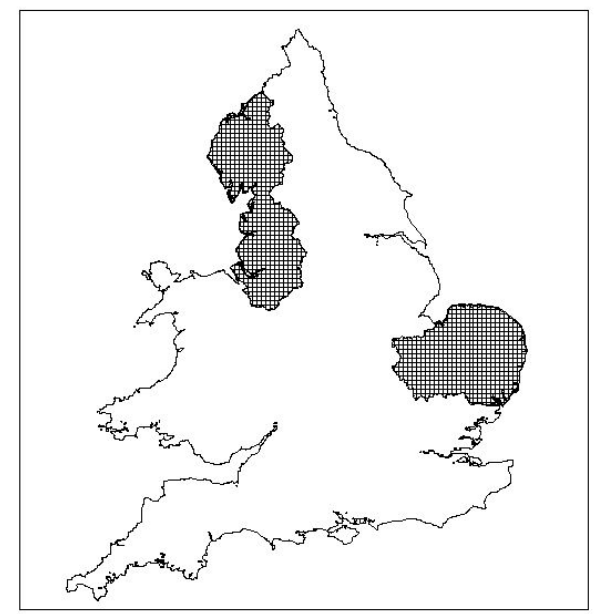

Figure 1 Map of England and Wales showing the East Anglian region modelled (right) and North West (top left) 


\section{Methodology}

\subsection{Agricultural metamodel}

The agricultural metamodel is derived from the full agricultural land use estimation model described in Rounsevell et al. (2003) and Holman et al. (2005a). The method combines a crop model which predicts the yield of a wide range of crops as a function of climate and soil type, with a farm model (SWFM) which determines the optimum cropping given crop gross margins, labour and machinery costs and soil workability of a generic farm. In order to differentiate the functions of the models and to allow the user to observe the effects of changes to separate aspects, two metamodels, one for each component model, were created and combined.

A considerable amount of data are available from outputs of the full models for both the North West and East Anglia, for current climate and the 2050 Low, Medium and High climate scenarios (UKCIP98; Hulme et al., 1998) and for all the main soil types found in these regions. The outputs are crop yield, crop maturity date, area of each crop and farm profit, plus other derived information such as water use and nitrate leaching. They are a function of very detailed input data on soils, weather data, machinery use, etc. The metamodels are developed to emulate the output using reduced detail input data.

\subsubsection{Crop metamodel}

The format of a typical file of soil data is shown in Figure 2. Soils typically have 3 to 4 soil horizons, each with different soil parameters and a rooting depth up to $150 \mathrm{~cm}$. The first step was to derive parameters which described the main features of these data which influence the crop yield, namely those which influence the availability and storage of water. The soil data were characterised by:

○ the available water content to $100 \mathrm{~cm}$ depth and $150 \mathrm{~cm}$ depth (2 parameters)

0 the proportion of this water available between five suction levels between Wilting Point and Field Capacity as a percentage of the $150 \mathrm{~cm}$ total. (4 parameters)

- surface soil texture index, estimated using the formula $\operatorname{Int}[(4 c+2 z+d-78) / 22.2]$ where $c, z$, and $\mathrm{d}$ are the percentage clay, silt and sand respectively and $\operatorname{Int}[\mathrm{x}]$ is the integer part of $\mathrm{x}$. The index increases as the soil becomes heavier - more clayey than sandy (1 parameter).

- rooting depth, surface horizon hydraulic conductivity and wilting point soil moisture water content (3 parameters).

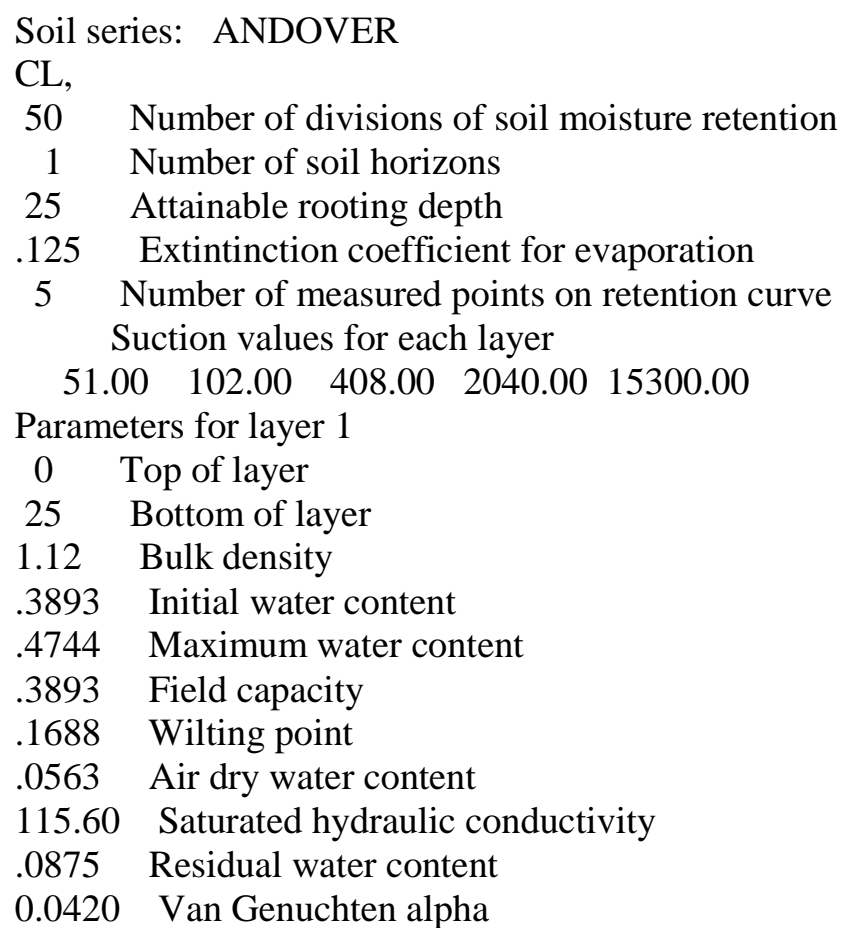

Figure 2 Typical soil data file used as input data by the full crop model 
The weather data used by the full crop model consists of the daily air temperature (max and min), rainfall, potential evapo-transpiration and radiation. The climate data, from which the daily data were originally generated, consist of monthly means. Climate change scenarios are generally characterised in terms of changes in 'winter' or 'summer' half-year precipitation and temperature. The weather data were therefore characterised as:

○ annual rainfall and percentage in summer;

- average summer temperature and difference from average winter temperature;

$\circ$ annual potential evapo-transpiration and percentage in summer.

The latitude, carbon dioxide level, which increases yield, and amount of irrigation complete the characterisation of the data used by the crop model.

The procedures for deriving a metamodel for each crop, using artificial neural networks (ANN) are described in Appendix 1. Figure 3 illustrates the results for winter wheat. Tests of the resulting model showed responses which were in accord with expectations. However use of the networks with extreme situations has sometimes shown less reasonable responses. This is to be expected as the metamodel has no mechanistic understanding within it, so that using the model outside the training set is very inadvisable. Such responses could also indicate deficiencies with the training set or even deficiencies in the original mechanistic model.

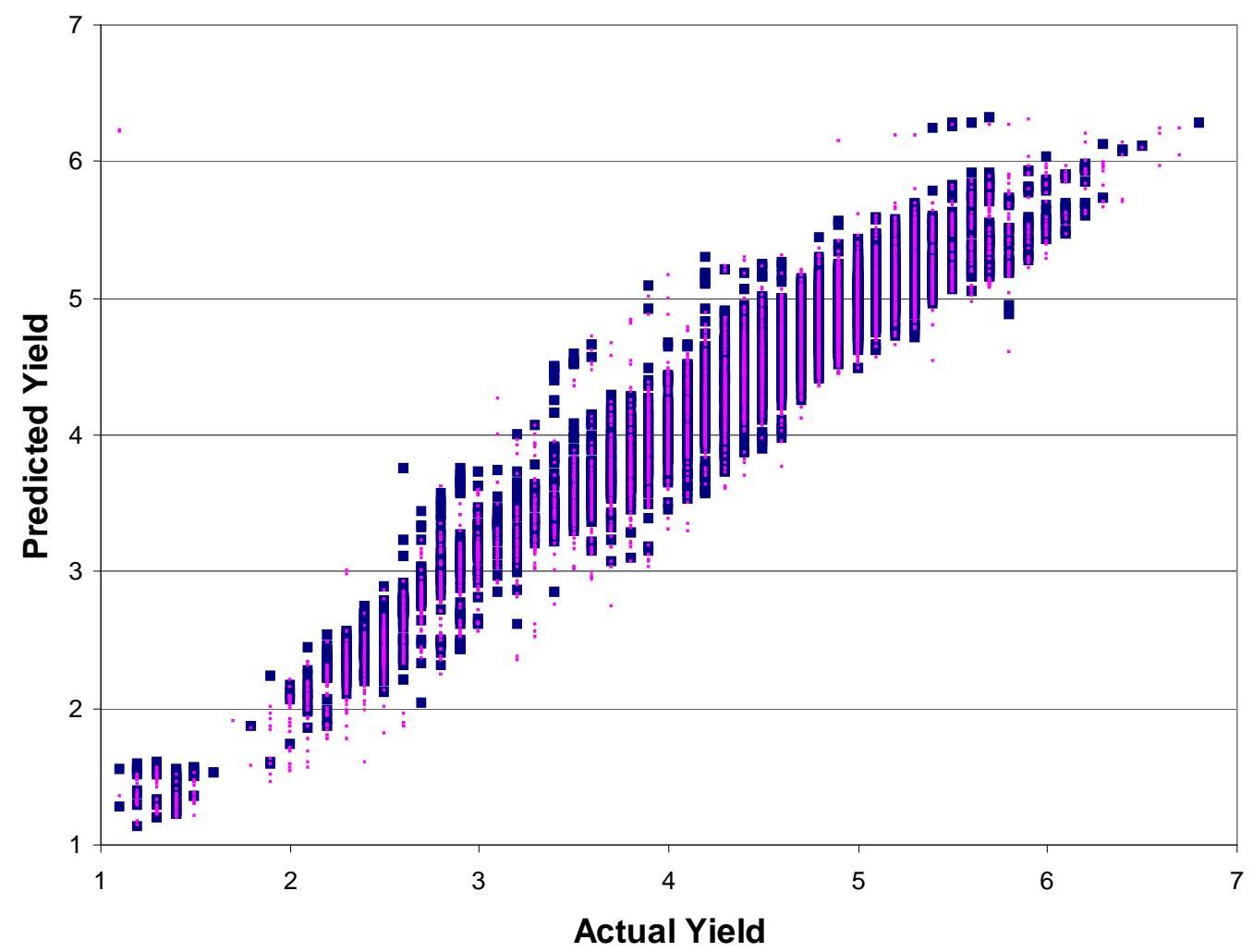

Figure 3 Performance of neural network for winter wheat yield $(t / h a)$ - the yield predicted by the neural network is plotted against the actual yield from the full model which the neural network seeks to emulate.

\subsubsection{Farm model}

The main input to the farm model is the crop gross margins which, given the above crop yields, can be calculated from the crop prices, subsidies and variable costs. As in the full model, calibration adjustments were made to the output of the crop model. Data are available from the farm model database which is based on East Anglia, from the farm management literature (Nix 2004, ABC 2005) and from Defra statistics on cropping in England and Wales. In general yields need to be increased to match present day levels and reduced in areas of high rainfall to allow for the effects of disease and 
harvest losses. Changes in crop yields for crops not simulated were estimated as pro-rata changes in those of a similar crop type that were simulated

The farm model estimates the area of each crop that a farm would grow in order to maximise profit. The crops available to the model were restricted in Rounsevell et al. (2003) and that restriction has been continued. Thus oilseed rape represents all break crops that can be combine harvested, such as peas and beans, even though it is not nitrogen fixing. However the break crop sunflowers, which are not currently a major crop, are modelled separately in order to examine their potential with increasing temperature. Potatoes represent irrigated vegetables. Sugar beet is currently not grown across the whole of England due to the availability of processing factories, but all crops were modelled in both regions to examine the potential for crops in the future. Note that the crop model may indicate that conditions are climatically unsuitable for a crop.

The input data are characterised by:
$\circ$ crop gross margin of each crop $(\mathrm{g})$
○ soil texture index (s)
○ workable hours in the winter (w)
- final date of grass harvesting (proxy for maturity date of each crop) (m)
$\circ$ winter rainfall (r)
○ summer evaporation (e)
- change in labour and machinery costs $(\eta)$

For the two irrigated crops, sugar beet and potatoes, the model selects the version for which the level of irrigation $(0,100 \mathrm{~mm}, 200 \mathrm{~mm})$ gives the highest gross margin, dependent on the availability of water (Henriques et al., 2007).

A regression approach was adopted to predict the percentage of the area under each crop, using as the primary variables the ratios between the gross margin of the target crop and its competitors, with other regressions such as winter workable hours. Given the cropping, the number of animals, other expenditure and finally the profit can be derived. 4264 data points were available for each scenario. Appendix 1 describes the detail of the modelling procedure.

Finally nitrate leaching was estimated using a relationship fitted to the output from the full crop model. This estimates leached nitrogen as a proportion of excess nitrogen (applied minus crop offtake) given the soil index and winter rainfall. Nitrogen applied is assumed to be proportional to expected yield.

\subsubsection{Analysis procedure}

Table 1 Example of soil information for each grid. $S=$ soil number, $P=$ proportion of the grid.

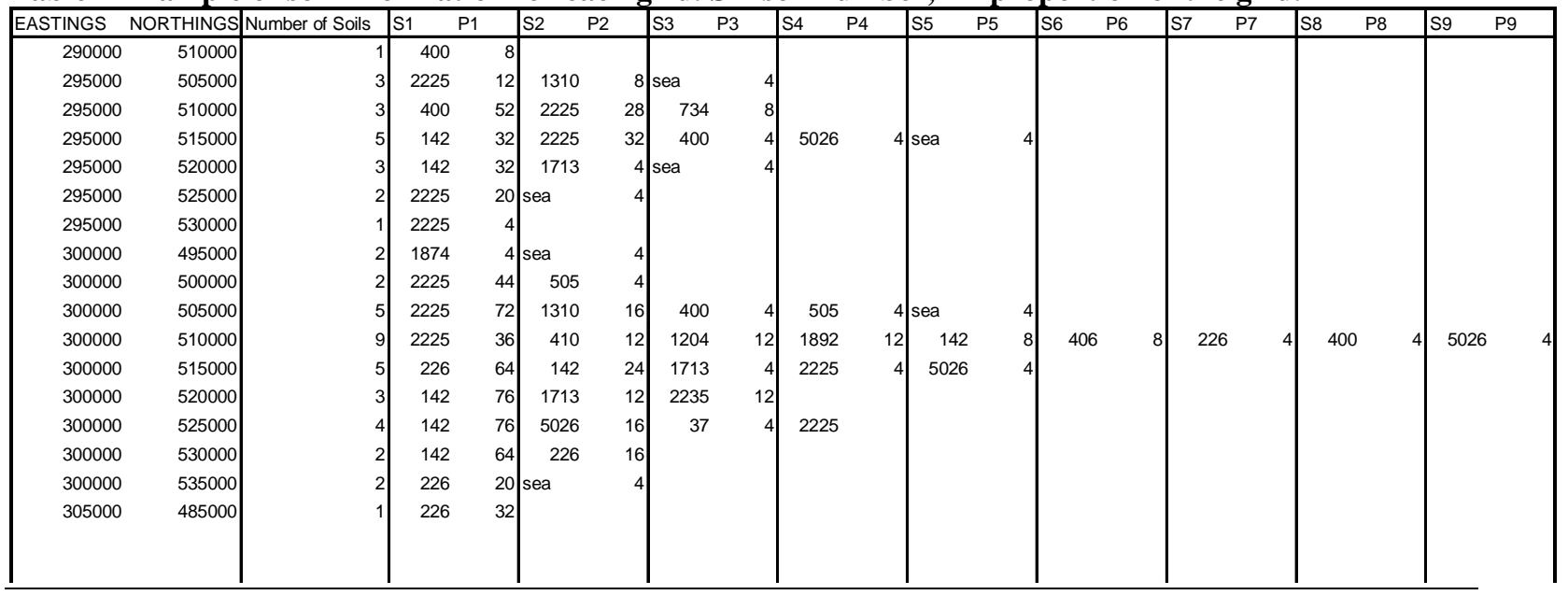

Gridded data at a $5 \times 5 \mathrm{~km}$ resolution are available from the 1:250,000 scale National Soil Map of England and Wales (Mackney et al., 1983) and from the UKCIP02 climate scenarios (Hulme et al. 
2002). Due to mapping differences, these are not identical and the first step is to produce a merged set of $5 \times 5 \mathrm{~km}$ grids. Each grid contains areas (cells) classified as different soil types, as shown in Table 1. For each soil type there is detailed information on typical soil properties. Some cells only contribute a very small area of the grid, so a minimum threshold of 100ha was set for a cell to be included; this gives 3526 and 3820 cells in the East Anglia and North West regions respectively.

Based on the soil and current climate, the cells were combined into 46 and 181 clusters respectively, to be analysed by the metamodels (see Appendix 1). The most typical member of each cluster is analysed by the metamodels and the results are then applied to all the cells in that cluster.

The areas of each grid available for agriculture are determined using data from the Centre for Ecology and Hydrology's Land Cover Map 2000 (available on http://www.magic.gov.uk/) to identify agriculture, urban, forested and 'other' land. As far as possible, poor soils are correlated with 'other' land use. Urban land use is assumed to be independent of soil. The flood metamodel (Richards et al., this volume) identifies areas which either cannot be designated as agriculture because of frequency of flooding (assumed to be currently classified as 'other'), or can only be grassland (assumed currently 'agriculture - grass'). This then provides the baseline areas where the agricultural model can be applied. Results from the agricultural model classify land as intensive agriculture if profit is greater than $£ 21,700 / 100$ ha, extensive agriculture if profit is greater than $£ 9,300 / 100$ ha and otherwise as abandoned. This gives the level of production of each commodity and irrigation used in each region.

In future scenarios, additional areas are removed for urban use in proportion to the scenario-defined change in population, and the areas of flooding identified by the flood metamodel may either increase or decrease. The scenarios also define any forested area change.

\subsubsection{Production required and irrigation available}

Previously in Holman et al (2005a) prices for crops have been set in the scenarios. This mostly gave very extreme answers such as outcomes comprising either large areas of sugar beet and potatoes or none, or even no cropping whatsoever. The economics of supply and demand mean that in cases of low supply, prices will rise and in cases of over-supply, prices will fall. As we are only modelling a small region, this is complicated by what other UK regions will produce as well as imports and exports. The approach taken in this analysis is for the scenario to specify the change in level of production required from a region and for the model to adjust prices to approximately fit this target level of production (see Appendix 1). The production required in a scenario is defined using two parameters - one to change all baseline production pro-rata, and one to increase bio-energy production.

\subsubsection{Outputs}

Outputs are calculated by $5 \times 5 \mathrm{~km}$ grid cell and by region, which can be displayed or used by subsequent models as described in Holman et al. (2007):

- By 5 x $5 \mathrm{~km}$ grid cell (displayed as maps): Percentage cropping by crop, production of each commodity (000t by crop), nitrate leaching ( $\mathrm{kgN} / \mathrm{ha}$ ), land use (urban, forest, other), irrigation water used (Ml).

- By region (displayed as graphs): Land use type (arable, intensive grass, extensive grass, abandoned; \% of grid), percentage regional cropping, irrigation water used (Ml), nitrate leaching $(\mathrm{kgN} / \mathrm{ha})$, land use (urban, forest, agriculture, other), production of each commodity (000t by crop).

Outputs passed to other models: Profit ( $£ / h a), \mathrm{N}$ fertiliser inputs (tonnes per grid cell), pesticide inputs; \% of grid in intensive arable cropping, land use type (arable, intensive grass, extensive grass; $\%$ of grid), winter versus spring crops; $\%$ of grid winter and spring sown crops), agricultural land abandoned; $\%$ of grid).

\subsubsection{Interactive input parameters}

The system uses as its starting point the scenarios developed in Holman et al. (2005) which are described by storylines. The climate scenarios are those developed on behalf of the United Kingdom Climate Impacts Programme (UKCIP02) which are expressed monthly means, on a $5 \mathrm{x} 5 \mathrm{~km}$ grid. 
The socio-economic scenarios are shown in Table 2. The storylines are converted to the large number of specific input parameters required by the models, such as percentage increases in population or crop yields (Holman et al., 2005). By selecting a climate and a socio-economic scenario, default values are set for a wide range of input parameters. The parameters that are directly relevant to the agricultural model are listed in Table 3. A user can then interactively examine the impact of these individual parameters. There are no restrictions on the combinations of values which the user can select although some are identified as improbable futures. In general, values are expressed as a change from current as $100 \%$. The user is unable to change some parameters of the scenarios, notably the percentage setaside and crop subsidy structure.

Table 2 Description of the 4 socio-economic scenarios

\begin{tabular}{|l|l|l|l|}
\hline & \multicolumn{1}{|c|}{ Regional } & Global \\
\hline Enterprise & $\begin{array}{l}\text { Economically 'bullish', } \\
\text { Markets } \\
\text { to promote and maintain their in a highly } \\
\text { distinctive qualities with } \\
\text { economic support } \\
\text { competitive world with } \\
\text { a free market emphasis. }\end{array}$ & $\begin{array}{l}\text { Regional Enterprise (RE) } \\
\text { and the environment. Economic } \\
\text { subsidies are uniform (or zero), water } \\
\text { resources are managed as a national- } \\
\text { level resource }\end{array}$ \\
\hline Sustainability & $\begin{array}{l}\text { Subsidy payments and } \\
\text { environmental taxation } \\
\text { are used to move } \\
\text { agriculture away from } \\
\text { intensification. Regional Stewardship (RS) }\end{array}$ & Global Markets (GM) \\
\hline
\end{tabular}

Table 3 The parameters directly relevant to the agricultural model. Unless otherwise specified, the values are expressed as a change from current as $100 \%$. The socio-economic values are for 2050. 2020 values are calculated pro-rata.

\begin{tabular}{|c|c|c|c|c|c|c|}
\hline \multirow{2}{*}{\multicolumn{3}{|c|}{ Socio-economic scenario }} & GS & GM & $\mathbf{R S}$ & $\mathbf{R E}$ \\
\hline & & & 130 & 170 & 115 & 150 \\
\hline \multirow{2}{*}{\multicolumn{2}{|c|}{ Regional bio-energy production, '00PJ }} & \begin{tabular}{l|l} 
EA \\
\end{tabular} & 329 & 104 & 273 & 160 \\
\hline & & NW & 57 & 18 & 48 & 28 \\
\hline \multicolumn{3}{|c|}{ Yield change due to technology } & 115 & 150 & 103 & 160 \\
\hline \multicolumn{3}{|c|}{$\begin{array}{l}\text { Change in crop variable costs (a combination of fertiliser, } \\
\text { sprays, seed, etc) }\end{array}$} & 80 & 135 & 60 & 160 \\
\hline \multicolumn{3}{|c|}{ Change in agriculture capital costs (eg labour costs) } & 170 & 200 & 130 & 130 \\
\hline \multicolumn{3}{|c|}{$\begin{array}{l}\text { Water available for irrigation, } \mathrm{Ml} / \text { day } \\
\text { (note this is over-ridden if the irrigation cost is changed) }\end{array}$} & 200 & 420 & 300 & 420 \\
\hline \multicolumn{3}{|c|}{$\begin{array}{l}\text { Irrigation efficiency (mm water used to get present } 100 \mathrm{~mm} \\
\text { effect) }\end{array}$} & 210 & 170 & 190 & 170 \\
\hline \multicolumn{3}{|c|}{$\begin{array}{l}\text { Cost of irrigation (note this is normally overridden by water } \\
\text { available) }\end{array}$} & 170 & 100 & 190 & 120 \\
\hline \multicolumn{3}{|c|}{ Setaside, $\%$ of arable crop } & 8 & 0 & 12.1 & 10 \\
\hline \multirow{2}{*}{\multicolumn{2}{|c|}{$\begin{array}{l}\text { Subsidy, \% of current wheat } \\
\text { (crop subsidies are as per CAP 2000) }\end{array}$}} & Area & 100 & 0 & 100 & 0 \\
\hline & & Crop & 0 & 0 & 100 & 100 \\
\hline \multicolumn{3}{|c|}{ Fertiliser cost } & 194 & 150 & 186 & 163 \\
\hline \multicolumn{3}{|l|}{ Climate scenario } & $2020 \mathrm{~L}$ & $2020 \mathrm{H}$ & $2050 \mathrm{~L}$ & $2050 \mathrm{H}$ \\
\hline$\%$ change from current & \multicolumn{2}{|c|}{$\begin{array}{l}\text { annual temperature, }{ }^{\circ} \mathrm{C} \\
\text { summer precipitation } \\
\text { winter precipitation }\end{array}$} & $\begin{array}{c}+0.8 \\
-6 \\
+3\end{array}$ & $\begin{array}{c}+1.0 \\
-7 \\
+3\end{array}$ & $\begin{array}{l}+1.5 \\
-11 \\
+5\end{array}$ & $\begin{array}{c}+2.3 \\
-18 \\
+8\end{array}$ \\
\hline
\end{tabular}

\subsection{Cereal field margin species model}

The SPECIES model (Spatial Estimator of the Climate Impacts on the Envelope of Species; Pearson et al., 2002; Harrison et al., 2006) was used to simulate the impacts of climate change on the potential 
geographical distribution of six plant species associated with cereal field margin habitats. SPECIES employs an ANN to define bioclimate envelopes based on inputs generated through a climatehydrological process model. The model is trained using existing empirical data on the European distributions of species at a $0.5^{\circ}$ latitude/longitude resolution to enable a wide climate space to be characterised that captures the climatic range of future scenarios. Once a network is trained and validated at the European scale, it is then applied at a finer $5 \times 5 \mathrm{~km}$ spatial resolution within the East Anglian and North West regions.

Model performance was statistically analysed using the Area Under the Receiver Operating Characteristic Curve (AUC) - AUC is a measure of prediction accuracy derived from the Receiver Operating Characteristic (ROC) curve (Fielding and Bell, 1997). The ROC curve describes the compromise that is made between the sensitivity (defined as the proportion of true positive predictions versus the number of actual positive sites) and false positive fraction (the proportion of false positive predictions versus the number of actual negative sites). AUC ranges from 0.5 for models with no discrimination ability, to 1 for models with perfect discrimination. Further details concerning model validation are provided in Pearson et al. (2004). AUC statistics were greater than 0.9 for all six species, indicating very good discrimination ability.

Predictions of potential climate space from the SPECIES model were combined with outputs on the area of arable land and nitrogen use from the agricultural metamodel to simulate the impacts of climate and socio-economic changes on the suitability of cereal field margin species at the regional scale. The area of arable land was simply applied as a habitat mask. The effects on plant species of nitrogen fertiliser use were simulated by applying thresholds based on an individual species' sensitivity to nitrogen derived from the Ellenberg indicator values for Britain (Hill et al., 1999). The species were divided into classes indicating low, medium or high tolerance to nitrogen increases, as the Ellenberg values are on an arbitrary scale and species' ecological requirements may vary in different parts of their range and according to local conditions, thus a broader classification was appropriate (

Table 4). Galium aparine (cleavers) was assigned to the most tolerant class (class 1). Papaver dubium (long-headed poppy), Papaver rhoeas (field poppy) and Silene gallica (Spanish catchfly) were assigned to class 2, whilst Legousia hybrida (Venus' looking glass) and Scandix pecten-veneris (shepherd's needle) were assigned to the least tolerant class (class 3).

Table 4 Species' sensitivity thresholds for nitrogen related to absolute values of nitrogen fertiliser use (kg/ha) from the agricultural land use model.

\begin{tabular}{clcc}
\hline \multicolumn{2}{c}{ Species nitrogen (N) sensitivity } & \multicolumn{2}{c}{ Thresholds (kg/ha N) } \\
\hline Class & Description & Stressed & Unsuitable \\
\hline 1 & Tolerant of N increase & 270 to 300 & $>300$ \\
2 & Some tolerance of N increase & 240 to 270 & $>270$ \\
3 & Little tolerance of N increase & 210 to 240 & $>240$ \\
\hline
\end{tabular}

\section{Results}

3.1 Validation of the agricultural land use metamodel

Table 5 compares the results of the baseline agricultural metamodel simulations with Defra census data. Note that not all permanent grassland is simulated by the farm model - only intensive grassland such as for dairy cows, not upland and rough grazing. Also the model predicts the long-term steady state structure of farming given a set of expected prices at a point in time, whereas farm structure actually changes at a slower rate. The results for East Anglia are good. For the North West the results are generally good, with a possible tendency to over-predict winter wheat, though the census data probably includes grassland which has been classified as 'other' land from the Land Cover Map in the model. The differences in irrigation are insignificant. Figure 4 shows a comparison of the predicted area of winter wheat by the metamodel and the full farm model. A regression of these data shows that where the full model would predict zero, the metamodel tends to predict about $7 \%$ of the area as winter wheat. The full model itself may also be over-predicting winter wheat in the North West, partly due to the fact that the model permits farms with small areas of cereals and partly due to 
not modelling the effect of the transport to factories which would reduce the on-farm value of small volumes of winter wheat at remote locations. Sugar beet is also permitted even with no factory nearby in order to assess whether in the future with increased temperatures there would be sufficient production of the crop to justify a factory.

Table 5 Comparison of baseline output from ANN farm model with 2001 June census. Note that the farm model does not model all permanent grass - only intensive lowland grass such as for dairy cows.

\begin{tabular}{l|c|c|c|c}
\hline \multicolumn{1}{c|}{$\%$ crop } & \multicolumn{2}{c|}{ June census 2001 } & \multicolumn{2}{c}{ Farm model } \\
\hline Wheat & East Anglia & North West & East Anglia & North West \\
\hline Winter barley & 39 & 3 & 42 & 12 \\
\hline Spring barley & 9 & 2 & 11 & 4 \\
\hline Potatoes & 8 & 6 & 13 & 9 \\
\hline Sugar beet & 4 & 1 & 4 & 2 \\
\hline $\begin{array}{l}\text { Oilseed } \\
\text { rape/peas/beans }\end{array}$ & 14 & 1 & 8 & 2 \\
\hline Grass & 16 & 83 & 11 & 70 \\
\hline Forage maize & 1 & 2 & 8 & 0 \\
\hline & & & 2 & 855 \\
\hline Irrigation(tcm) & 86804 & 3765 & 84476 & \\
\hline
\end{tabular}

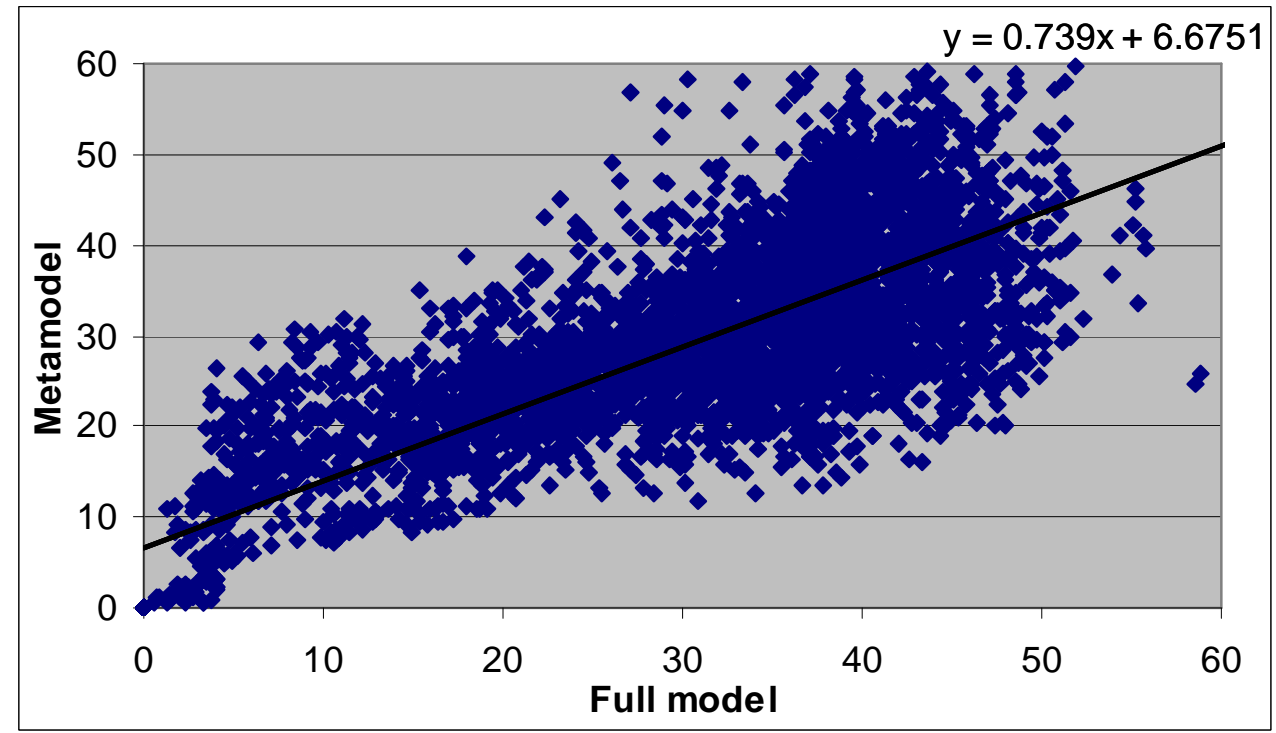

Figure 4 Comparison of full farm model area (\% of grid) of winter wheat and area predicted by metamodel for winter wheat showing regression line between full model and metamodel (both regions).

\subsection{Scenario studies for agriculture}

Results were obtained with the metamodel for 10 situations in order to explore both the impact of various scenarios and the performance of the model:
a) baseline
b) 2050 Low (climate) with Global Market (economics)
c) 2050 High (climate) with Global Market (economics)
d) 2050 High (climate) with Regional Stewardship (economics)
e) As c) but with highest credible temperature and winter precipitation and lowest credible summer precipitation
f) As b) but with lowest credible temperature and highest credible winter and summer precipitation


g) As c) but with highest irrigation water available, $672 \mathrm{Ml} / \mathrm{d}$ (East Anglia only)

h) As c) but with lowest irrigation water available, $168 \mathrm{Ml} / \mathrm{d}$ (East Anglia only)

i) With all parameters set at their highest setting

j) With all parameters set at their lowest setting

Note that (e) and (f) test the effects of climate scenario uncertainty where the credible slider range was determined from an analysis of outputs from multiple global climate models (as given in Hulme et al., 2002), and (i) and (j) represent highly improbable scenarios to demonstrate the flexibility of the models.

Figure 11 shows the effects at the regional level which can be displayed using the interactive program. The first graph shows the areas of crops and the second shows the equivalent tonnes of production. The third graph shows how other land uses change. The fourth graph shows the breakdown between spring and winter sowing, intensive grassland and agricultural land which becomes unprofitable and is either grazed extensively or abandoned. The fifth graph shows fertiliser use and nitrate leaching.

In East Anglia

- Cropping remains quite stable. Grassland is severely reduced in the 2050 High scenarios almost certainly due to the low yield in the drier conditions.

- Sunflowers are only selected in one scenario even though they are feasible in climate terms for all of them. The model's production-target approach means that sunflowers are effectively competing to produce oil with oilseed rape which has a higher yield.

- With all parameters at a minimum, oilseed rape is eliminated and $20 \%$ of the area is unprofitable for intensive agriculture. This also generates the highest price for water $(250 \%$ of current) due to the very low rainfall and availability. Conversely the all-max scenario generates the lowest price $(24 \%)$ due to the combination of very high yields, rainfall and availability. This demonstrates the model is capable of making extreme changes where it is appropriate.

- Nitrate leaching increases as fertiliser use increases with the large increases in crop yields in the GM scenarios, because fertiliser requirement is proportional to expected yield. The largest increase occurs with all parameters set to their maximum values, which is mainly a reflection of the very high rainfall thus selected.

- Large increases in bioenergy demand make it impossible to supply the total demand for arable products.

- Reductions in irrigation water availability translate into a reduction in potato production.

- Urban land use decreases in RS because the scenario assumes depopulation of East Anglia and increase of forests, but owing to the economics, agricultural land use is least in this scenario.

The changes can be difficult to relate to one cause. In particular, where the demand for both food and energy exceeds feasible production, no cropping solution will meet the demands and the amount by which demand is not met will be distributed among the crops at random.

In the North West

- There is a very much greater range of outcomes in this region

- All future scenarios suggest a reduction in grassland with the greatest in the $2050 \mathrm{High}$ climate scenario combined with the Regional Stewardship socio-economic scenario $(2050 \mathrm{H}+\mathrm{RS})$.

- In the RS scenario, the low level of demand for milk products, which can easily be supplied from a smaller area, and the flat subsidy structure encourages the widest range of break cropping.

- The reduction in grassland shows a clear correlation with increased climate change. With lower temperatures grassland is at similar levels to the baseline.

- In a reversal of the East Anglia situation, having all parameters set to their maximum values causes some land to become abandoned. The demand for a high production level of milk forces it to be satisfied but at a high price (twice present), though due to the large yield increases a relatively modest area is needed. The demand for arable crops in the North West 
is also easily satisfied. The high rainfall and costs make any additional production generally uneconomical and thus the balance of land becomes extensive.

- Sustainability scenarios (RS and GS) cause the greatest reductions in grassland.

Figure 12 to Figure 14 show a selection of the spatial effects displayed by the interface for East Anglia. The overall levels obviously reflect those in the Figure 11 and, in some cases, the fixed ranges for the shading obscure the fact that spatially the pattern in the scenario is identical to that in the baseline. Figure 12 shows the proportion of each grid square that is winter wheat for the baseline and two future 2050s scenarios. In both the future scenarios shown there is a clear tendency to a more even spread of winter wheat than in the baseline, particularly in the RS case, driven by the high flat level of subsidy, where $52 \%$ of grids are in the range where $30-40 \%$ of the grid is winter wheat.

Figure 13 illustrates the irrigation demand for the same scenarios which shows the same spreading effect in the RS scenario. The Global Markets scenario shows both a reduction in the areas with no irrigation and those with the maximum level. Both show a reduction in irrigation, which may seem counter-intuitive, but it is driven by the imposed limit on available water. The map shows the levelling effect of the high level of crop-independent subsidy.

Figure 14 examines the effect of increasing irrigation water availability on potatoes. There is a clear increase in area as irrigation availability increases from $168 \mathrm{Ml} / \mathrm{d}$ to $420 \mathrm{Ml} / \mathrm{d}$, but thereafter no increase.

Figure 15 and Figure 16 show a selection of the spatial effects displayed by the interface for the North West region for the baseline and two future scenarios. Figure 15 illustrates the increasing area of winter wheat grown in the North West in the 2050 scenarios with the crop moving to the north of the region, where it now becomes more profitable. Figure 16 shows the corresponding data for intensive grassland. Note that these figures are the percentage of the grid area not of the agricultural area, so that areas of high urbanisation appear as very low, even if most of the non-urban land is grass.

\subsubsection{Examining the sensitivities of the results to climate change}

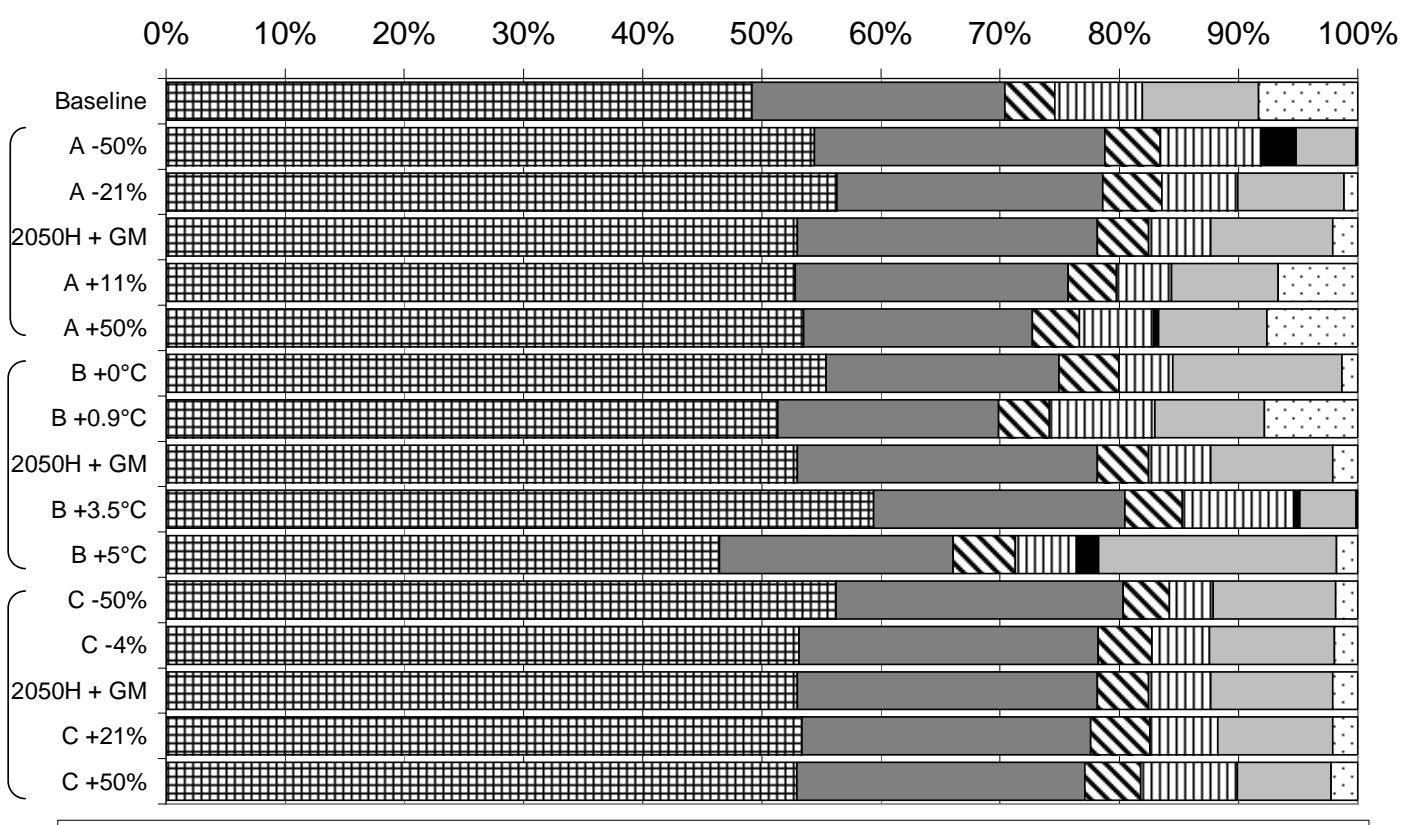

田\%Wheat $\square \%$ Barley $\mathbf{\Delta} \%$ Potatoes $\mathbb{0} \%$ Sbeet $\mathbf{\square} \%$ Sunflower $\square \%$ Oilseed rape $\square \%$ Forage

Figure 5 The sensitivity of the cropping for East Anglia for scenario 2050High+GlobalMarket to A) summer precipitation change B) annual temperature change and C) winter precipitation change percentage of area in each crop. 
Figure 5 and Figure 6 show a study of the sensitivity of the conclusions to the climate change uncertainty. The analysis is repeated using different rainfall and temperature assumptions. The values shown on the graph above and below the default value for the scenario $(2050 \mathrm{H}+\mathrm{GM})$, are the upper and lower credible changes and the upper and lower extreme changes. Figure 5 for East Anglia shows that the summer precipitation increasing by $11 \%$, instead of decreasing by $18 \%$, would almost return the cropping to the current distribution - further increases would have little more effect. Extremely low values (decreasing by 50\%) would eliminate grass (shown as forage) and encourage sunflowers. Increased summer temperatures have similar effects to reducing summer precipitation. Winter precipitation is not important. Figure 6 for North West shows that for summer precipitation only very high levels (that is increasing by $50 \%$, instead of decreasing by $16 \%$ ) make a notable difference, causing arable cropping to be unattractive. However both higher and lower levels of annual temperature increase the forage area. Winter precipitation is again unimportant.

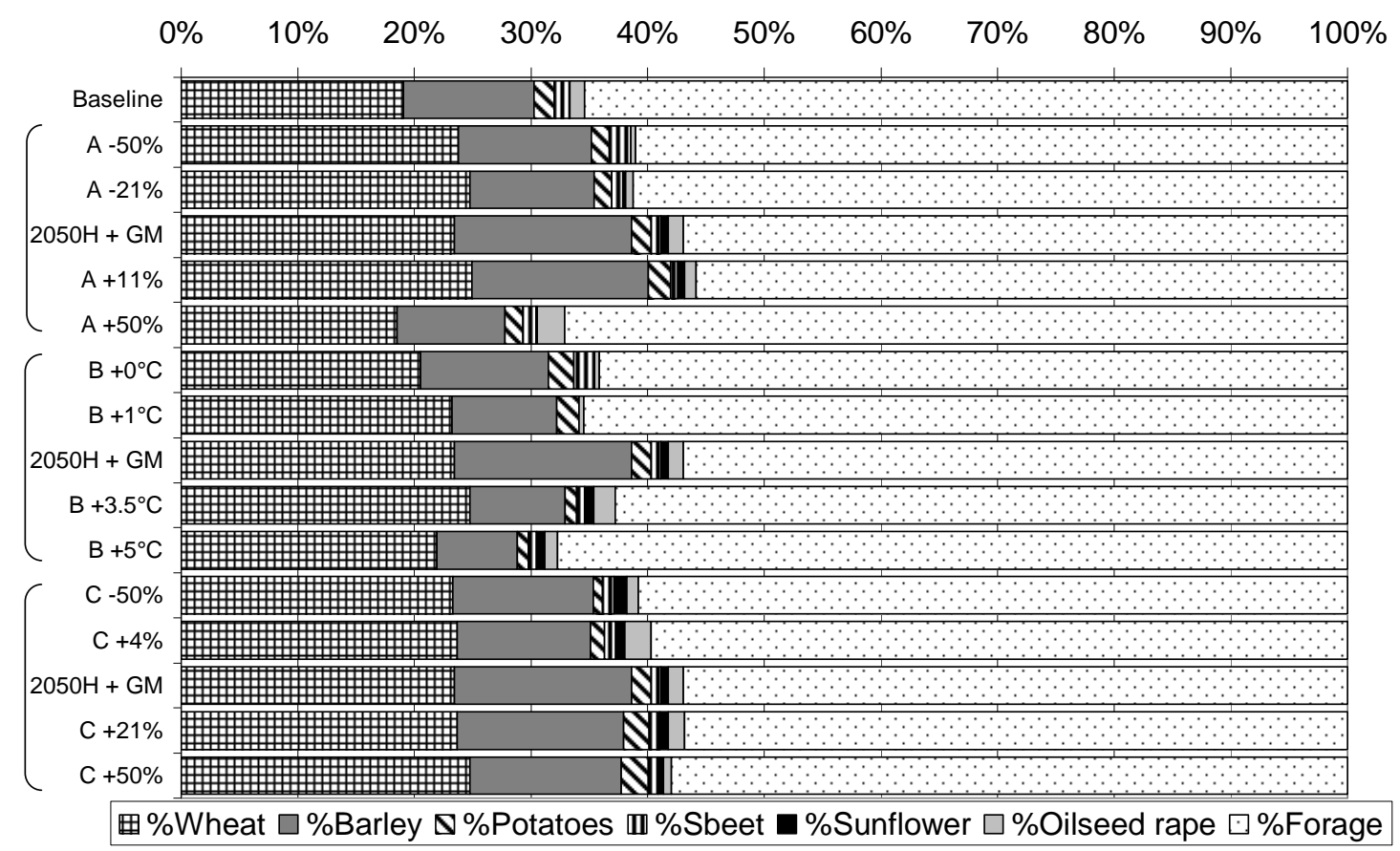

Figure 6 The sensitivity of the cropping for North West for scenario 2050High+GlobalMarket to A) summer precipitation change (default scenario: -16\%) B) annual temperature change (default scenario: $+2.1^{\circ} \mathrm{C}$ ) and $\mathrm{C}$ ) winter precipitation change (default scenario: $+8 \%$ ) - percentage of area in each crop.

\subsection{Effect on species}

None of the six species modelled lose climate space in East Anglia, but they all gain some climate space in the North West ranging from 2\% for Papaver rhoeas to $62 \%$ for Legousia hybrida under the 2050 High scenario. Arable land use is widespread in East Anglia and using land use data from the agricultural model to mask out cells with only non-arable land extracts only $3 \%$ of cells under all the scenarios, which are mainly situated around the coast. For the North West region, arable land use is gradually gained as the climate change scenarios become more severe, with the number of cells containing some arable land increasing from $70 \%$ for the baseline climate up to $91 \%$ under the 2050 High scenario, due to arable cultivation becoming profitable at higher elevations in the north and east of the region. Differences between the socio-economic scenarios are much smaller, ranging from 90 to $92 \%$ of cells when combined with the 2050 High climate scenario, with the Global Markets and Regional Enterprise scenarios resulting in slightly less arable land use than the Global Sustainability and Regional Stewardship scenarios.

In contrast, the effects of nitrogen fertiliser use on the suitability of species shows much greater differences between the socio-economic scenarios, as illustrated in Figure 7 for the East Anglia case 
study region. Suitability for $S$. pectin veneris, which has a low tolerance to nitrogen, is lowest under the Regional Enterprise scenario where between 20 and $27 \%$ of grid cells are classified as being marginal due to nitrogen stress, whilst between 4 and $8 \%$ are classified as unsuitable. This is followed by the Global Markets scenario, where between 13 and 17\% are classified as marginal due to nitrogen stress, whilst approximately $1 \%$ are unsuitable. Finally, the Global Sustainability and Regional Stewardship scenarios show all grid cells to be suitable. It can also be noted from Figure 7 that that the suitability is slightly worse under the 2050 Low climate scenario combined with the different socio-economic scenarios than the 2050 High scenario, because as shown in Figure 11 there is slightly more nitrogen input in the former case.

Differences between the three classes of species' sensitivities to nitrogen increases are shown in Figure 8 for the North West region under the 2050 Low and Regional Enterprise scenario. Only 3\% of grid cells are classified as marginal due to nitrogen stress for the most tolerant species, Galium aparine. For Papaver rhoeas (medium tolerance), $13 \%$ are marginal and $4 \%$ become unsuitable due to nitrogen increases. The least tolerant species, Legousia hybrida, shows $12 \%$ of grid cells becoming marginal and $16 \%$ becoming unsuitable due to nitrogen stress. Results for other species are similar to those illustrated in

Figure 8 for the relevant tolerance class.

(a)

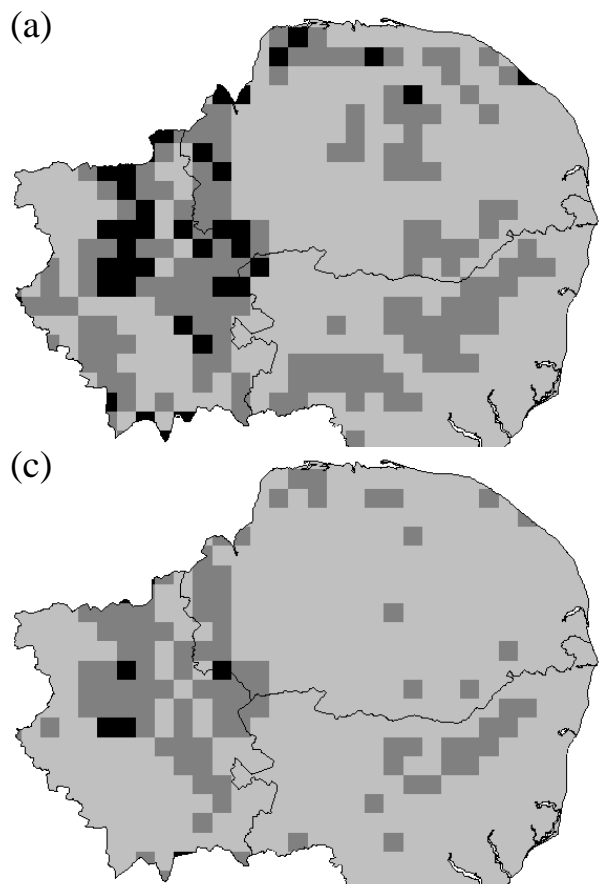

(e)

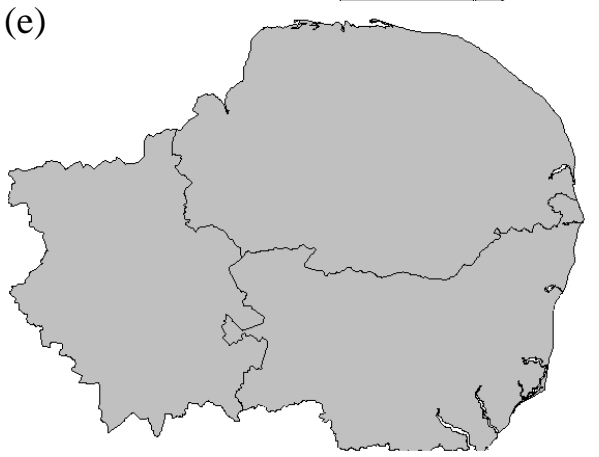

(b)

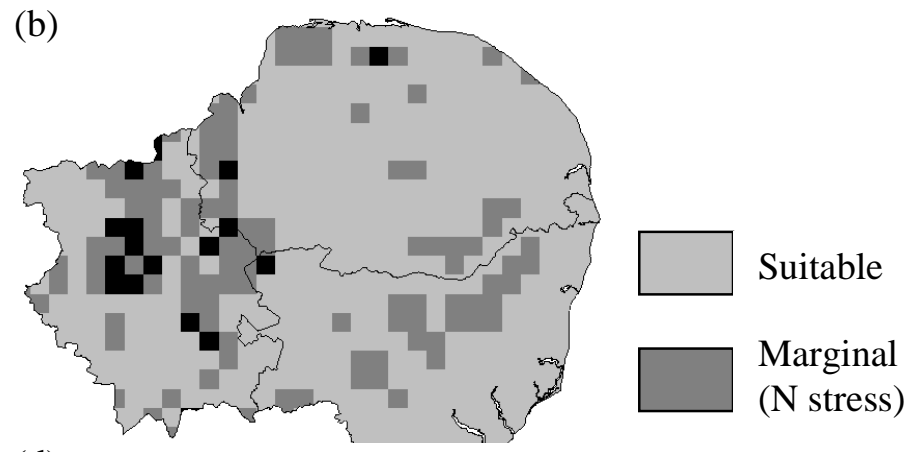

(d)

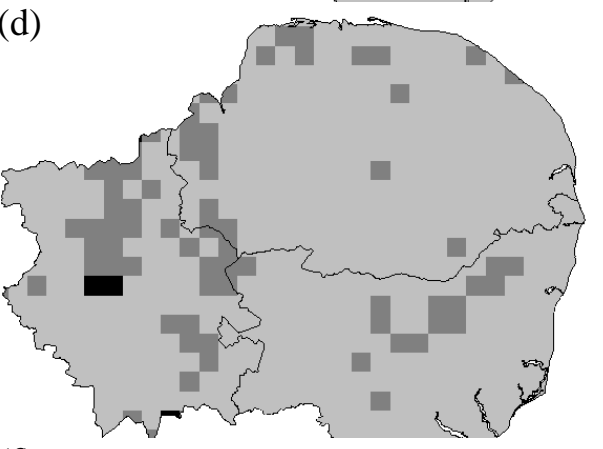

(i)

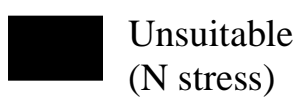

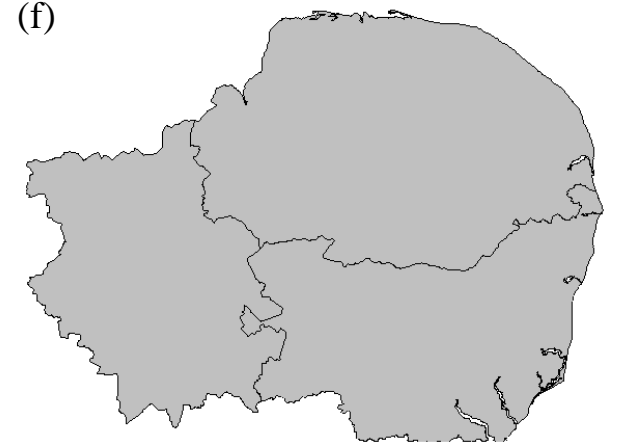

Figure 7 Suitability for Scandix pectin veneris in East Anglia: (a) 2050Low+RegionalEnteprise; (b) 2050High+RegionalEnterprise; (c) 2050Low+GlobalMarket; (d) 2050High+GlobalMarket; (e) 2050Low+RegionalStewardship; and (f) $2050 \mathrm{High}+$ RegionalStewardship. Note that the results for the GlobalSustainability socio-economic scenario are the same as shown for RegionalStewadship. 

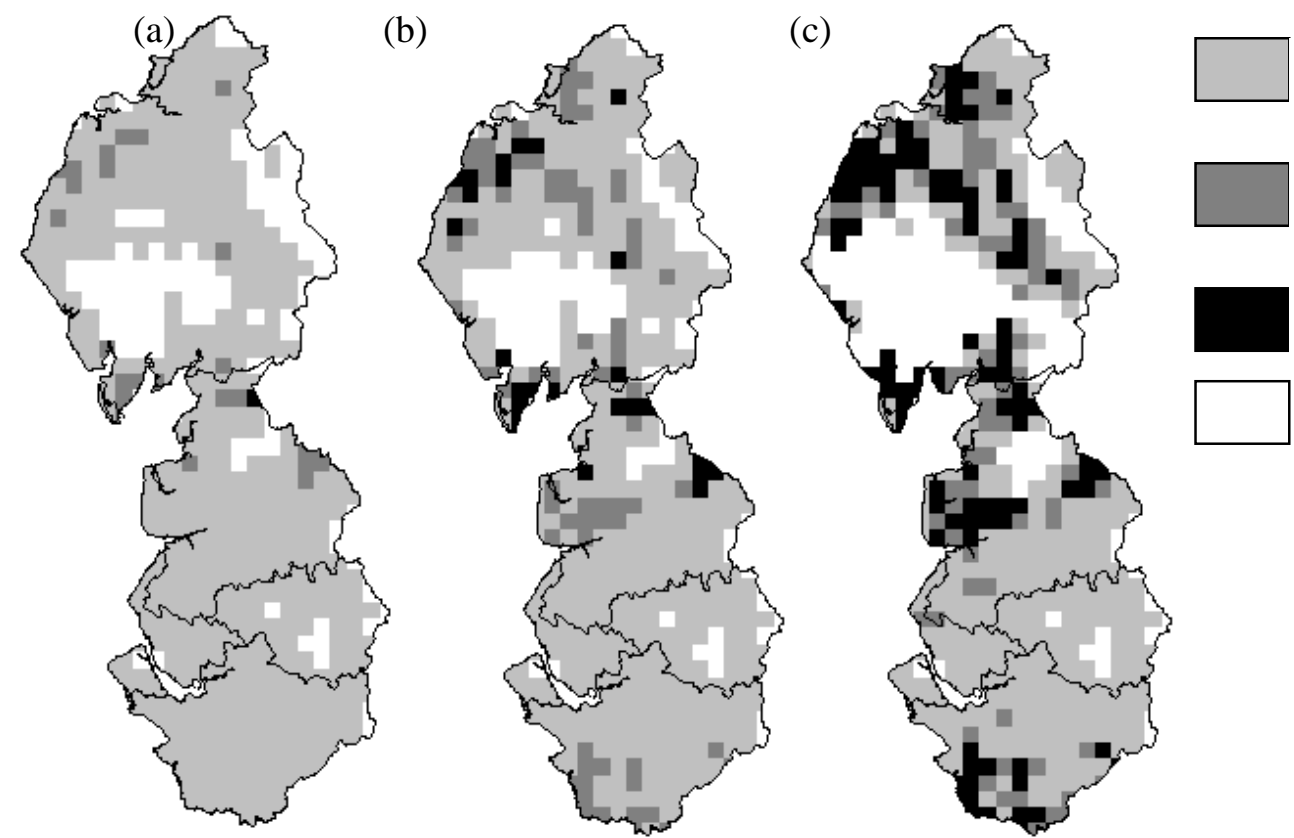

Suitable

Marginal

(N stress)

Unsuitable

(N stress)

Unsuitable

(climate space or habitat)

Figure 8 Species suitability in north west England, for three species with different nitrogen tolerances under the 2050Low+RegionalEnterprise scenario: (a) Galium aparine (high tolerance); (b) Papaver rhoeas (medium tolerance); and (c) Legousia hybrida (low tolerance).

These results show that the levels of nitrogen fertiliser use would not negatively impact on G. aparine under most scenarios, as it is particularly responsive to nitrogen (Froud-Williams, 1985). It is a common weed in cereal field margins and can interfere with harvesting and lead to crop contamination (Taylor, 1999). In experiments on its impact on yields, losses in winter wheat of 30\%, $47 \%$ and $52 \%$ were reported at densities of 25,100 and 520 plants per $\mathrm{m}^{2}$ (Froud Williams, 1985). G. aparine, along with $P$. rhoeas and Anisantha sterilis (Barren brome) have been shown to compete increasingly effectively with spring wheat with increasing levels of nitrogen (Lintell Smith et al., 1992). It can be effectively controlled by the use of herbicides (Lutman et al., 1988) and so it could be adversely affected if these increases in nitrogen inputs were associated with a concomitant increase in its abundance and thus in herbicides usage. This increase in nitrogen could also lead to a decrease in abundance of P. dubium and S. pecten-veneris (MacNaughton and Harper, 1964 and Wilson and King, 2003 respectively). The results show that those species with a low or medium tolerance to nitrogen inputs are likely to become significantly affected under the Regional Enterprise and Global Markets socio-economic scenarios. This is because their growth response to the increased nitrogen inputs is lower than the crop and other more competitive species, such as G. aparine, and thus they are increasingly suppressed through competition (Wilson and King, 2003). Tall growing species, like Papaver spp., may reach crop canopy height, but are unable to compete with the crop's response to nitrogen, while lower growing species, such as S. pecten-veneris are affected on both accounts. This reduced productivity will affect their reproductive capacity and thus contribute to their decline in abundance, as has already been seen over the last 50 years.

In order to reduce the impacts on species with low and medium tolerances to nitrogen, a possible adaptation option would be to restrict chemical inputs. This can be implemented through changing the crop variable costs within the agricultural metamodel. Although this is a composite variable of which currently $40 \%$ represents fertiliser, it is assumed that any reduction represents a switch from chemical to organic nitrogen inputs (greater use of nitrogen fixing crops). Crop variable costs under the 2050 Low and Regional Enterprise scenario were reduced from $160 \%$ to $125 \%$ of current. The impact of nitrogen fertiliser on suitability is greatly reduced, as illustrated in Figure 9 for S. pecten veneris in East Anglia. Here, the number of grid cells classified as marginal due to nitrogen stress are reduced from 27 to $0.5 \%$, and those classified as unsuitable due to nitrogen are reduced from 8 to $0 \%$. 
Already there are several agri-environment schemes targeted at decreasing the impacts of nitrogen inputs on biodiversity and research has shown that reductions in fertiliser usage can lead to the restoration of habitats and species (Mountford et al., 1996; Critchley et al., 2004). The adoption of such a policy though, depends on the socio-economic scenario, being less likely under Global Markets type of future scenario.

(b)

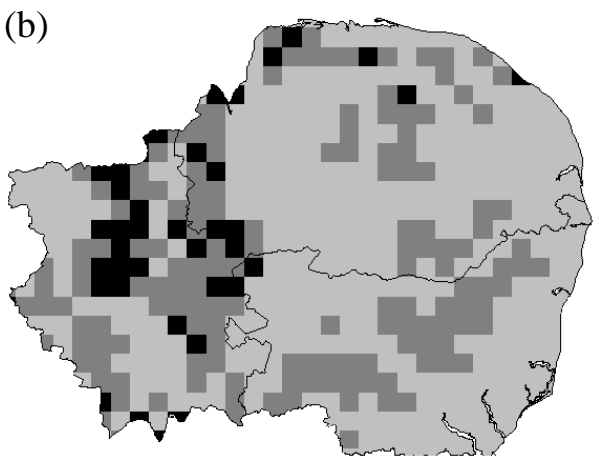

(b)

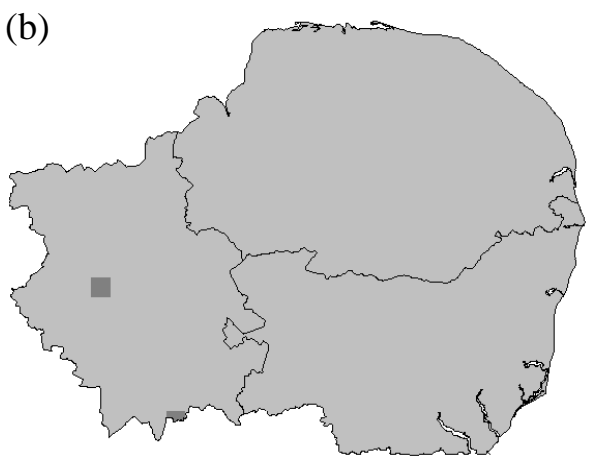

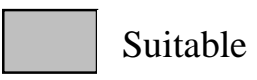

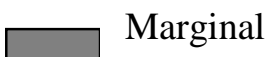

( $\mathrm{N}$ stress)

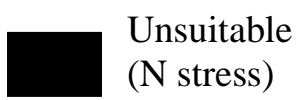

Figure 9 Adaptation option for reducing nitrogen stress for Scandix pectin veneris under the 2050Low+RegionalEnterprsie scenario: (a) using default crop variable costs of $160 \%$ of current; and (b) using reduced crop variable costs of $125 \%$ of current.

\section{Discussion}

The major advantage of the metamodel approach is the large number of analyses that can be carried out in a short space of time, which it is difficult to do justice to in a paper such as this. A single run of the whole system typically takes about 20 seconds (Holman et al., 2007), though speed of computer has a large impact, as does the number of habitats selected for analysis. Of this the agriculture metamodels take 1.5 seconds. This enables impacts to be studied in far more detail, though it frequently raises new questions as to why a response happens. This should however be viewed in a positive light as, where previously the answers were simply a black box to be taken on trust, it is now possible for a user to study what is happening in response to changes in some detail. The fact that it leads to questions enables the research to move forward either to explain the results (by providing more detail in the output), expand on the options available (more input parameters), or correct the functioning of the models - which may be a fault in the underlying model or in the metamodel representation.

A major disadvantage remains the time taken for a solution. Although 20 seconds is not long, it remains restrictive in trying to view a change in a result versus a change in a parameter. Metamodels are also not the same as the full models. There remains a need for greater study of the responses of the metamodels to ensure they do not contain hidden unexpected correlations that only become apparent at extreme values. Some areas have already been resolved, such as the negative quadratic response of a crop to its gross margin - so that at very high gross margins, none of the crop was grown. A problem was also identified where the area of wheat was correlated with a high gross margin of grass - a reflection of the fact that areas that are very good for one crop are generally very good for all crops.

The setting of production level not price in a scenario has not resolved all the problems with unreasonable cropping solutions. For several of the standard scenarios it is impossible to meet the production demanded (largely due to the demand for bio-energy), which causes prices to increase to potentially unreasonable levels. Because there is no associated model for the areas outside the two regions modelled (UK or world) to determine the potential for imports or exports, the production level merely implies that all land in the region, which could reasonably be used for agriculture, is used. It leaves the question of whether the shortage of supply should transfer to another region.

Information on the tolerances of individual species to nitrogen fertilisers is generally limited and a subject of debate. Researchers such as McCloskey et al. (1996) have found that the impacts of the 
cultivation management regime on 12 arable weeds (including G. aparine and $P$. rhoeas) may outweigh those of the amount and form of fertiliser used, while Lintell Smith et al. (1999) found that the level of nitrogen inputs did not affect the life cycle stages of A. sterilis. This may be due to compensatory changes in the effects of intra-specific competition (Lintell Smith et al., 1992). Other studies have suggested that nitrogen application can be detrimental to arable species, especially those which are less competitive (Wilson and King, 2003). Hence, the results from the biodiversity model for cereal field margin species should be treated with due caution bearing in mind that the thresholds for the three tolerance classes had to be defined from the scant data available and expert opinion. The sensitivity of the cereal field margins modelling to the input threshold values has not been tested and future work could include the use of various parameterisations for each species, so that different 'scenarios' of potential nitrogen impacts can be derived.

\subsection{Scope for improvement}

The evaluation of the REGIS2 tool showed that users were broadly satisfied with this system (Holman et al, 2007). Run time was of concern. The main areas for improvement can be divided into the speed of the system (for which agriculture is a small part), user interaction and the accuracy and detail of the modelling (which can be sub-divided into the full model and its metamodel representations). In addition our own examination of the system has shown some areas where performance of the models was poor. The following summarises some of the improvements likely to make most impact:

Speed

- Replace the slow parts of the system with faster metamodels

- Improve coding of existing metamodels to eliminate wasteful calculations

User interaction

- Divide some of the agricultural input parameters into their components such as fertilisers and sprays, production levels of each commodity, yield increases of individual crops

- Provide more detail of the output in response to user requirements

Accuracy - metamodels

- Improve detail of interactions between yield, chemical and organic fertiliser, and spray costs and restrictions

- Improve performance of farm metamodels for extreme values of gross margins

- Improve performance of price/production iteration method

Accuracy - full models

- Improve performance of the crop models

- Improve performance for identifying potential agricultural land where currently it is not.

\section{Conclusions}

Agricultural land use in East Anglia shows little change in the balance of arable cropping due to climate but a substantial reduction in the already small area of grassland in the 2050 High climate scenarios. Large increases in bio-energy demand make it impossible to supply the total demand for arable products. Reductions in irrigation water availability translate into a reduction in potato production. The North West shows increasing arable cropping with consequent reductions in grassland as future temperatures increase. Sustainability scenarios cause the greatest reductions in grassland. These conclusions are stable over quite a large range of temperature assumptions for the future climate and are independent of assumptions about winter precipitation.

These changes in cropping patterns could lead to an increase in habitat availability for cereal field margin species in the North West. In both regions, any changes in agricultural inputs need to be coupled with the sensitivity of the species and the modelling has shown how species intolerant of high nitrogen conditions could be impacted under future socio-economic scenarios.

Linking the agricultural and biodiversity metamodels in an integrated system and including metamodels for flooding and water resources (Henriques et al, 2007) enabled knock-on effect and feedbacks between the different sectors to be analysed in a way that would not be possible in a purely sectoral modelling study. 
The research has shown it is possible to produce an interactive system to allow a detailed examination of the impact of a wide range of climate change and socio-economic change parameters on the future of agriculture and associated species in spatial detail. The resulting time for one run of the analysis is still longer than desirable at 20 seconds but nevertheless is sufficient to stimulate users to ask questions about the cause of responses observed to changes in parameters. Perhaps even more importantly it enables the researchers themselves to carry out far more analyses than was previously possible and thus lead to the identification of improvements needed to the analyses. However there remains a conflict between the desire for speed of analysis and the desire for increased detail of analysis, which, ironically, being impractical was previously not an issue. 


\section{Appendix 1: Metamodel procedures to predict cropping and profit for a soil climate combination}

\section{Crop model}

The available data to derive a metamodel for each crop consisted of up to 12000 data points, fewer where the crop did not mature. Artificial neural networks (ANN) were fitted to this data using QNet (2000). The first step is to select a training data set from the full set which covers the full range of values of each of the input variables. A description of the number of layers used is given in Table 6 . For a full 17_10_5_1 network with no connections removed, the number of fitted parameters are $(17+1) * 10+(10+1) * 5+(5+1) * 1$. The minimum correlation required from the test set for a fit to be accepted was 0.95 . Figure 3 illustrates the results for winter wheat. Tests of the resulting model showed responses to major variables (Figure 10) which were in accord with expectations. However use of the networks with extreme situations has sometimes shown less reasonable responses. This is to be expected as the metamodel has no mechanistic understanding within it so that using the model outside the training set is very unadvisable. Such responses could also indicate deficiencies with the training set or even deficiencies in the original mechanistic model.

Table 6 Description of neural networks used for fitting crop yields

\begin{tabular}{l|c|c}
\hline \multicolumn{1}{c|}{ Crop } & $\begin{array}{c}\text { Network } \\
\text { structure }\end{array}$ & $\begin{array}{c}\text { Minimum } \\
\text { summer } \\
\text { temperature }\end{array}$ \\
\hline Winter Wheat & $17-10-5-1$ & - \\
\hline Spring barley & $17-10-5-1$ & - \\
\hline Spring oilseed rape & $17-5-2-2-1$ & - \\
\hline Potatoes & $18-10-5-1$ & 11.65 \\
\hline Sugar beet & $18-10-5-2-1$ & 12.55 \\
\hline Sunflowers & $17-10-5-1$ & 14.65 \\
\hline Grass & $17-10-5-1$ & - \\
\hline
\end{tabular}

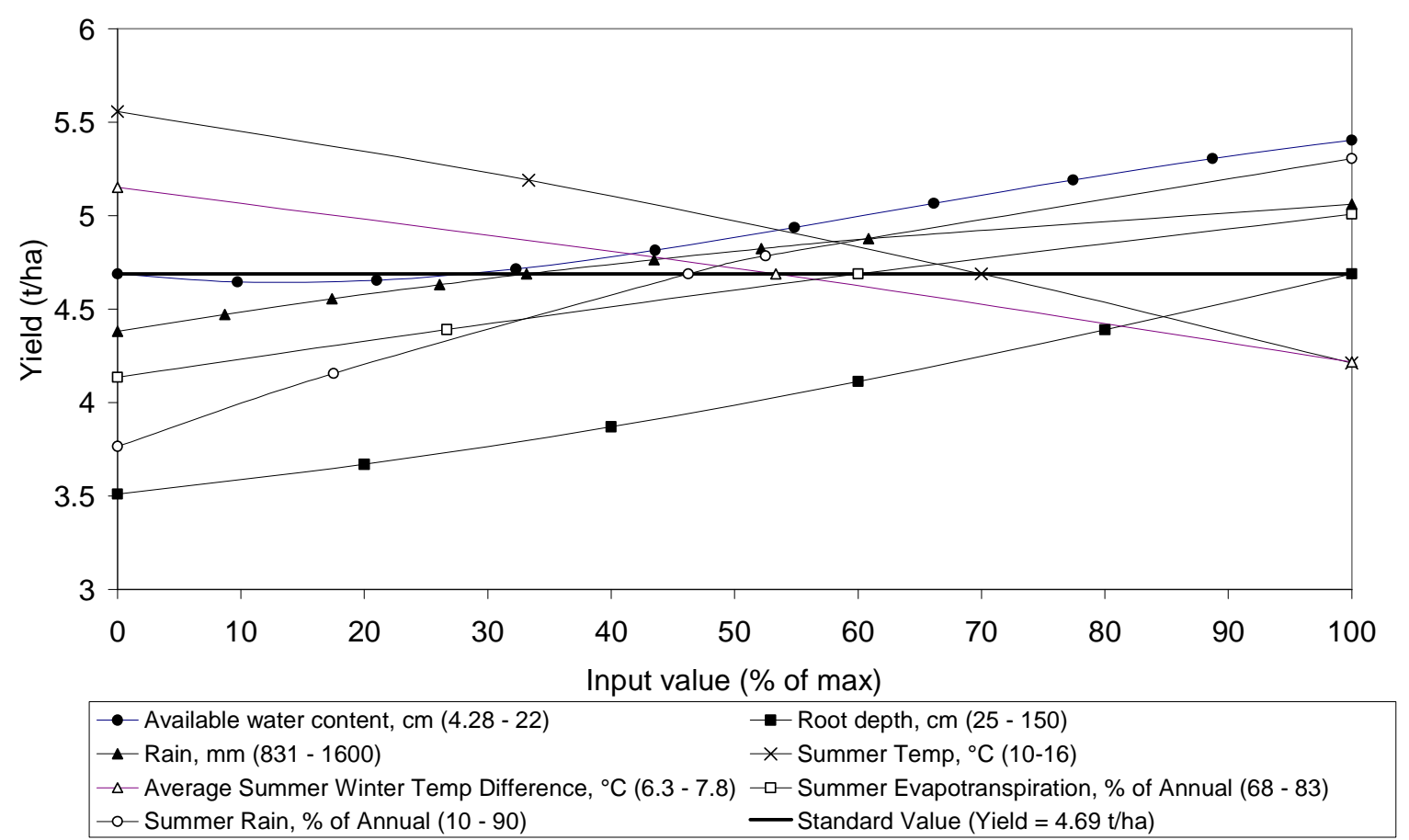

Figure 10 Testing the responses of the neural network predicting the winter wheat yield. Each line shows the effect on the output (yield) of changing a single input value over the specified range. 


\section{Farm model}

For each scenario, 4264 data points were available from runs of the full farm model for a wide range of soils and situations. In this case a regression type of approach was adopted to predict the percentage of the area in a given crop, using as the primary variables the ratios between the gross margin of the target crop and its competitors. Table 7 lists the regressions found. Where any fitted farm area is negative, the crop area is taken as zero. The final crop areas are then scaled to be $100 \%$ in total. For grass and winter wheat the fitted variable is: $\ln ((a+0.1) /(1+a+0.1))$ and for permanent grass: $a_{10}=\frac{100 \exp (X)}{100+\exp (X)}-a_{9}-0.1$ where $\mathrm{X}$ is given in Table 7 and $\mathrm{a}_{\mathrm{n}}$ denotes the area of crop n.

Table 7 Linear regression of crop area versus gross margin and soil type parameters. The input data are crop gross margin $(\mathrm{g})$, the soil index $(\mathrm{s})$, workable hours in the winter/1000 $(\mathrm{w})$, the maturity date $(\mathrm{m})$, autumn and spring rainfall ( $r_{-} a$ and $\left.r_{-} s\right)$, summer evaporation (e) and yield $(\mathrm{yN})$ of crop $\mathrm{N}$. For forage crops $\mathrm{g}$ is the yield*10 (dry matter yield for grass). $\mathrm{vN}$ is the ratio between the crop gross margin of crop $\mathrm{N}$ and the crop being fitted.

\begin{tabular}{|c|c|c|c|c|c|c|c|c|c|c|c|}
\hline $\mathrm{N}$ & 1 & 2 & 3 & 4 & 5 & 6 & 7 & 8 & 9 & 10 & 11 \\
\hline Crop & $\begin{array}{l}\text { Winter } \\
\text { Wheat }\end{array}$ & $\begin{array}{l}\text { Spring } \\
\text { Wheat }\end{array}$ & $\begin{array}{l}\text { Winter } \\
\text { Barley }\end{array}$ & $\begin{array}{l}\text { Spring } \\
\text { Barley }\end{array}$ & $\begin{array}{c}\text { Sugar } \\
\text { Beet }\end{array}$ & Potatoes & $\begin{array}{c}\text { Winter } \\
\text { OSRape }\end{array}$ & $\begin{array}{c}\text { Spring } \\
\text { OSRape }\end{array}$ & $\begin{array}{l}\text { Rot'l } \\
\text { Grass }\end{array}$ & $\begin{array}{l}\text { Perm } \\
\text { Grass }\end{array}$ & $\begin{array}{c}\text { Forage } \\
\text { Maize }\end{array}$ \\
\hline Const & -11.2 & -7.7 & -9.1 & -13.4 & -12.1 & -28.1 & 23.8 & -40.9 & -12.9 & -0.9 & 33 \\
\hline $\mathbf{s}$ & 0.2 & -0.1 & -8.5 & -0.2 & -0.1 & -7.3 & 5.3 & -0.2 & -3.9 & 0 & 0.1 \\
\hline $\mathbf{w}$ & 1.3 & 2.2 & -2.4 & 0.8 & 5.1 & 9.5 & 1.9 & 0.2 & -4.7 & -2.6 & -10.3 \\
\hline $1 / w$ & -0.03 & -0.15 & 0.21 & -0.17 & -0.03 & -0.51 & -0.34 & 0.02 & -0.46 & 16.2 & 0.01 \\
\hline $\mathbf{r} \_\mathbf{a}$ & 0.9 & & & & & & & & & & \\
\hline $1 / r_{-} \mathbf{s}$ & -0.2 & & & & & & & & & & \\
\hline v1 & & & 4.7 & 8.6 & 0 & 68.7 & -64.2 & 0.5 & 2.6 & -3.9 & 1.6 \\
\hline v3 & 5.8 & & & & & & & & & & \\
\hline v4 & & -12.5 & & & & & & 49 & & & \\
\hline v5 & -2.8 & -6.2 & 4.7 & -2 & & -18 & 5.3 & -18.4 & -44.9 & 7.3 & 87 \\
\hline v6 & & & & & -0.1 & & 29.5 & & & & \\
\hline v7 & -0.2 & & 4.3 & 3.2 & 0 & 0.3 & & & 8.2 & & 3.8 \\
\hline v8 & & 26.5 & & & & & & & & & \\
\hline v9 & 0.439 & 1.5 & 2.4 & 1.9 & 0.2 & 0 & -3.4 & -1.1 & & & -16.3 \\
\hline v11 & -0.01 & & & & & & & & -15.7 & & \\
\hline g & 0.002 & -0.068 & 0.017 & -0.053 & 0.005 & 0.017 & 0.07 & 0.051 & 0.667 & 0.099 & 0.254 \\
\hline $\mathbf{g}^{2}$ & & 0.588 & 0.037 & 0.67 & -0.014 & 0.026 & 0.221 & -0.012 & 0.374 & -2.48 & -3.603 \\
\hline $\mathbf{r}_{-} \mathbf{s}$ & & 20.2 & -37.3 & 19.9 & 7.4 & -4.3 & 43.7 & -2.2 & 9.9 & -7 & 20.5 \\
\hline $1 / \mathrm{e}$ & & & & & & & & & & 1.1 & \\
\hline $\mathbf{m}$ & & & & & & & & & & 90 & \\
\hline y10 & & 0.03 & 0 & 0.04 & 0.03 & -0.18 & -0.39 & -0.11 & & -0.01 & -0.39 \\
\hline y11 & & & & & & & & & -0.1 & & \\
\hline
\end{tabular}

The workable hours in winter is a function of the soil and rainfall:

$w=3347 \exp ((-6.714-3.07 s) r)$,

and the final date of grass harvesting:

$m=\operatorname{int}(-37.1+163 e+1.66 r+9.33 / e+0.567 / r+0.5)$.

Where $\mathrm{e}$ is the summer evapotranspiration

For future scenarios, the basic crop gross margins are initially adjusted for other factors: $g=p y \lambda+s-h(0.4 \lambda+0.6) v-t y \lambda \eta-I \tau-\psi m$ where $\mathrm{p}$ is the scenario crop price, $\mathrm{y}$ is the predicted yield, $\lambda$ the scenario increase in yield due to technology, $s$ the subsidy, $h$ the crop variable cost per hectare, $v$ the scenario increase in chemical costs, $\mathrm{t}$ is the crop variable cost per tonne, $\mathrm{I}$ is the amount of irrigation required adjusted for scenario efficiency changes, $\tau$ the scenario irrigation cost and $\psi$ a crop-dependent factor for delayed maturity. 
In order to calculate the profitability of a soil climate combination, a number of other variables are needed:

The number of cows, which may be zero, is calculated from the bulk fodder produced:

$C=0.0167 y_{g}+0.069 y_{m}$ where $\mathrm{y}_{\mathrm{g}}=$ total grass yield $(\mathrm{t})$ and $\mathrm{y}_{\mathrm{m}}=$ total maize yield $(\mathrm{t})$

Expenditure:

$E=51.0+0.000417 A+0.508 C-15.8 r-1.34 s-0.00544 w+129 / w+0.127 / s-0.872 m$

Profit, $£^{\prime} 000$ per ' 00 ha, is given by

$P=A / 1000+C g / 1000-E$,

where $\mathrm{A}$ is the sum of the crop gross margins and $\mathrm{g}$ is the cow gross margin.

\section{Spatial clustering}

Based on the soil and current climate, the cells were combined into 46 and 181 clusters respectively, to be analysed by the metamodels. The cluster analysis was carried out in Genstat (2004). A similarity matrix is constructed by calculating the Euclidean distance between each cell. The similarity matrix provides the input to the clustering procedure which uses agglomeration to add individuals to a group if its overall similarity at a given stage is greater than the current similarity level. The method of calculating the distance from a group can either be 'furthest', which produces very tight clusters or 'average' for less tightly knit clusters. The former was used for the North West because of the very large range of weather data. The process successively merges clusters/individuals at lower and lower levels of similarity, to produce a dendogram. The similarity threshold level of $97 \%$ was chosen to give the clusters used in the analysis. The most typical member of each cluster is analysed by the metamodels and the results are then applied to all the cells in that cluster.

\section{Price iteration}

The model iterates, altering the prices of crops and water, to obtain a level of production and irrigation within a pre-defined tolerance of the target production. Define $s=\left(p_{1}-p_{0}\right) /\left(f\left(p_{1}\right)-f\left(p_{0}\right)\right)$ where $\mathrm{p}$ is new price as a proportion of the baseline price (or irrigation level) and $f(p)$ is the commodity production $(000 \mathrm{t})$ or irrigation $(0000 \mathrm{~m} 3)$ at price $p$. If $\mathrm{s}$ is negative, this is a spurious effect of other changes, so price is not adjusted. The new ratio of the price to the baseline price is defined as $p^{*}=p_{1}+0.1 s\left(D-f\left(p_{1}\right)\right)$, where $\mathrm{D}$ is the required production. The maximum change permitted in one iteration is 0.2 . For East Anglia, milk production is unlimited and for the North West, arable production is unlimited.

\section{Acknowledgements}

This work was carried out as part of the RegIS2 project (CC0362) funded by the UK Department for Environment, Food \& Rural Affairs.

\section{References}

ABC (2005) The Agricultural Budgeting and Costing Book. Agro Business Consultants Ltd, Melton Mowbray.

Annetts, J.E., Audsley, E. (2002) Multiple objective linear programming for environmental farm planning. Journal of the Operational Research Society 53, 933-943.

Audsley, E., Pearn, K.R., Simota, C., Cojocaru, G., Koutsidou, E., Rounsevell, M.D.A., Trnka, M., Alexandrov, V. (2006) What can scenario modelling tell us about future European scale agricultural land use, and what not? Environmental Science \& Policy, 9, 148-162.

BAP (1995) Biodiversity: The UK Steering Group Report - Volume II: Action Plans (December 1995, Tranche 1, Vol 2, p235), HMSO London. http://www.ukbap.org.uk/UKPlans.aspx?ID=8

Berry, P.M., Rounsevell, M.D.A., Harrison, P.A. and Audsley, E. (2006) Assessing the vulnerability of agricultural land use and species to climate change and the role of policy in facilitating adaptation. Environmental Science and Policy, 9, 189-204. 
Berry, P.M., Dawson, T.P., Harrison, P.A, Pearson, R.G., Butt, N. (2003) The sensitivity and vulnerability of terrestrial habitats and species in Britain and Ireland to climate change. Journal for Nature Conservation, 11, 15-23.

Critchley, C.N.R, Burke, M.J.W., Stevens, D.P. (2004) Conservation of lowland semi-natural grasslands in the UK: a review of botanical monitoring results from agri-environment schemes. Biological Conservation, 115, 263-278.

Defra (2004) June Census Data. (published annually)

de Nijs, T.C.M., de Niet, R., Crommentuijn, L. (2004) Constructing land-use maps of the Netherlands in 2030. Journal of Environmental Management 72, 35-42.

Fielding, A.H., Bell, J.F. (1997) A review of methods for the assessment of prediction errors in conservation presence/absence models. Environmental Conservation, 24, 38-49.

Froud-Williams, R.J. (1985) The biology of cleavers (Galium aparine) In: Aspects of Applied Biology 9, The biology and control of weeds in cereals, pp. 189-195. AAB, Wellesbourne.

Genstat (2002) 6th Edition, VSN International, Hemel Hempstead, UK

Grime, J.P., Hodgson, J.G., Hunt, R. (1988) Comparative Plant Ecology. Unwin Hyman Ltd, London, $742 \mathrm{pp}$.

Harrison, P.A., Berry, P.M., Butt, N., New, M. (2006) Modelling climate change impacts on species. distributions at the European scale: Implications for conservation policy. Environmental Science and Policy, 9, 116-128.

Henriques, C., Holman, I., Audsley, E., Pearn, K. (2007) An interactive multi-scale integrated assessment of future regional water availability for agricultural irrigation in East Anglia and North West England. This issue

Hill, M.O., Mountford, J.O., Roy, D.B., Bunce, R.G.H. (1999) Ellenberg's indicator values for British plants. Ecofact Volume 2 Technical Annex, Institute of Terrestrial Ecology/Department of Environment Transport and the Regions, pp46.

Holman, I.P., Rounsevell, M.D.A., Shackley, S. (2007) Concepts for undertaking regional integrated climate change assessment. This issue.

Holman, I.P., Rounsevell M.D.A., Shackley S., Harrison P.A., Nicholls R.J., Berry P.M., Audsley E. (2005a) A regional, multi-sectoral and integrated assessment of the impacts of climate and socioeconomic change in the UK. I. Methodology. Climatic Change, 71, 9-41.

Holman, I.P. Nicholls, R.J. Berry, P.M. Harrison, P.A. Audsley, E. Shackley, S., Rounsevell, M.D.A. (2005b) A regional, multi-sectoral and integrated assessment of the impacts of climate and socioeconomic change in the UK. II. Results. Climatic Change, 71, 43-73.

Hossell, J.E., Jones, P.J., Marsh, J.S., Parry, M.L., Rehman, T., Tranter, R.B. (1996) The likely effects of climate change on agricultural land use in England and Wales. Geoforum 27, 149-157.

Hulme, M., Jenkins, G.J., Lu, X., Turnpenny, J.R., Mitchell, T.D., Jones, R.G., Lowe, J., Murphy, J.M., Hassell, D., Boorman, P., McDonald, R., Hill, S. (2002) Climate change scenarios for the United Kingdom. The UKCIP02 Scientific report. UKCIP, Oxford, UK.

Koomen, E., Kuhlman, T., Groen, J.,, Bouwman, A. (2005) Simulating the future of agricultural land use in The Netherlands. Tijdschrift Voor Economische en Sociale Geografie 96, 218-224.

Lintell Smith, G., Freckelton, R.P., Firbank, L.F., Watkinson, A.R. (1999) The population dynamics of Anisantha sterilis in winter wheat (comparative demography and the role of management. Journal of Applied Ecology, 36, 455-471.

Lintell Smith, G., Bayliss, J.M., Watkinson, A.R., Firbank, L.F. (1992) The effects of reduced nitrogen and weed competition on the populations of three common cereal weeds. Aspects of Applied Biology, 30, 367-372.

Lutman, P.J.W., Thornton, M.E., Lovegrove, A.W. (1988) Control of Galium aparine in winter cereals with mecoprop alone or with ioxynil plus bromoxynil. Weed Research, 28, 331-338.

Marshall, J., Brown, V., Boatman, N., Lutman, P., Squires, G. (2001) The impact of herbicides on weed abundance and biodiversity. PN0940, Pesticides Safety Directorate.

McCloskey, M.C., Firbank, L.G., Watkinson, A.R., Webb, D.J. (1996) The dynamics of experimental arable weed communities under different management practices. Journal of Vegetation Science, 7, 799-808.

McNaughton, I. H., Harper, J. L. (1964) Biological Flora of the British Isles. Papaver dubium. Journal of Ecology, 52, 780-783. 
Mackney, D., Hodgson, J.M., Hollis, J.M., Staines, S.J. [from contributions by the field staff] (1983) Legend for the 1:250,000 Soil Map of England and Wales. Soil Survey of England and Wales, Harpenden.

Mountford, J.O. Lakhani, K.H., Holland, R.J. (1996) Reversion of grassland vegetation following the cessation of fertilizer application. Journal of Vegetation Science, 219-228.

Munier, B., Birr-Pedersen, K., Schou, J.S. (2004) Combined ecological and economic modelling in agricultural land use scenarios. Ecological Modelling 174, 5-18.

Nix. J. (2004) Farm Management Pocketbook. Wye College.

Pearson, R.G., Dawson, T.P., Lui, C. (2004) Modelling species distributions in Britain: a hierarchical integration of climate and land-cover data. Ecography, 27, 285-298.

Pearson, R.G., Dawson, T.P., Berry, P.M., Harrison, P.A. (2002) SPECIES: a spatial evaluation of climate impact on the envelope of species. Ecological Modelling, 154, 289-300.

Preston, C.D., Pearman, D.A., Dines, T.D. (2002) New Atlas of the British Flora. Oxford University Press, Oxford, 910pp.

'Qnetv2000 Software package for Windows'. Vesta Services Inc, Winnetka, IL. 2000

Richards, Mokrech, Nicholls, Berry et al. (2007) Regional scale assessments of the impacts of climate change on coastal and fluvial ecosystems and the scope for adaptation. (this journal)

Rounsevell, M.D.A., Annetts, J.E., Audsley, E., Mayr, T. and Reginster, I. (2003) Modelling the spatial distribution of agricultural land use at the regional scale. Agriculture, Ecosystems \& Environment, 95 (2-3), 465-479.

Southeron, N.W. (1990) Conservation Headlands; a practical combination of intensive cereal farming and conservation. In: Firbank, L.G., Carter, N., Darbyshire, J.F., Potts G.R. (eds.) The Ecology of Temperate Cereal Fields. $32^{\text {nd }}$ Symposium of the British Ecological Society. Blackwell Scientific Publications, Oxford, pp 373-397.

Stewart, A., Pearman, D.A., Preston, C.D. (1994) Scarce Plants in Britain. J.N.C.C., Peterborough.

Sutcliffe, O.L., Kay, Q.O.N. (2000) Changes in the arable flora of central southern England since the 1960s. Biological Conservation, 93, 1-8.

Taylor, K. (1999) Biological Flora of the British Isles Galium aparine. Journal of Ecology, 87, 713730.

Wilson, P., King, M. (2003) Arable Plants - a field guide. WildGuides

Zander, P., Kachele, H. (1999) Modelling multiple objectives of land use for sustainable development. Agricultural Systems 59, 311-325. 


East Anglia
1 1)

$\begin{array}{llllll}0 \% & 20 \% & 40 \% & 60 \% & 80 \% & 100 \%\end{array}$

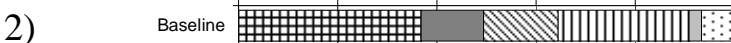

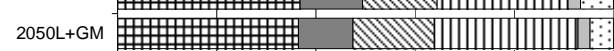

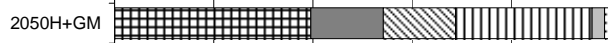

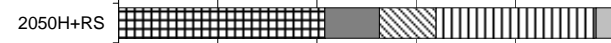
2050H+extGM 2050L+extGM 2050H+GM+maxwater ${ }^{2} \ldots$ 2050H+GM+minwater

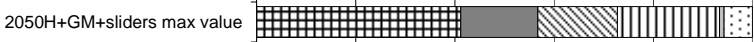

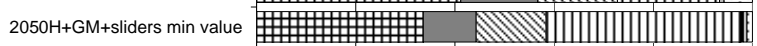
3)

田Wheat $\square$ Barley $₫$ Potatoes $\square$ SBeet Sunflower $\square$ Oilseed rape $\square$ Milk MI

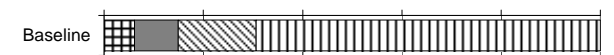

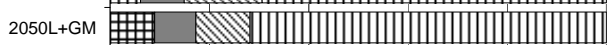

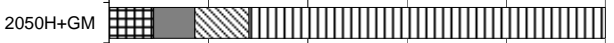

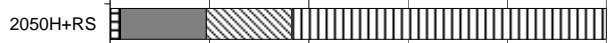

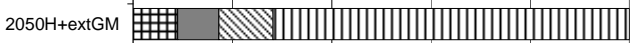
2050L+extG

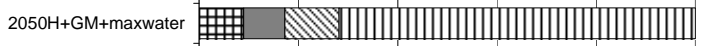

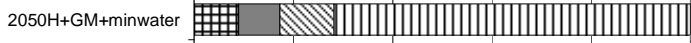

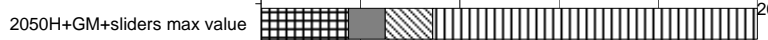

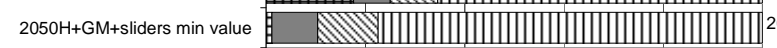

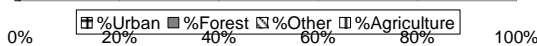

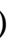

Baseline 2050L+GM 曲曲曲曲曲 2050H+GM

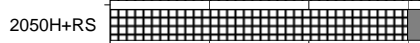
$2050 \mathrm{H}+$ extGM 2050L+extGM 2050H+GM+maxwater 2050H+GM+minwater

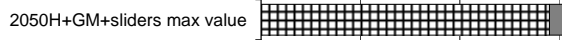

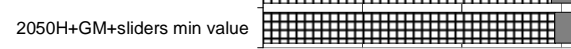

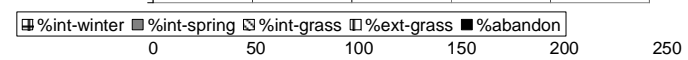

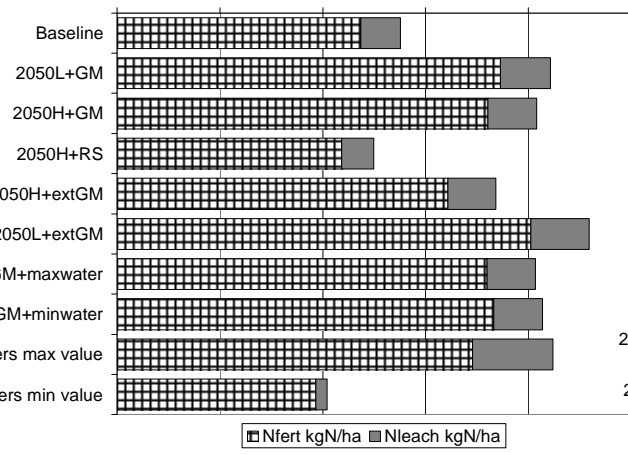

North West

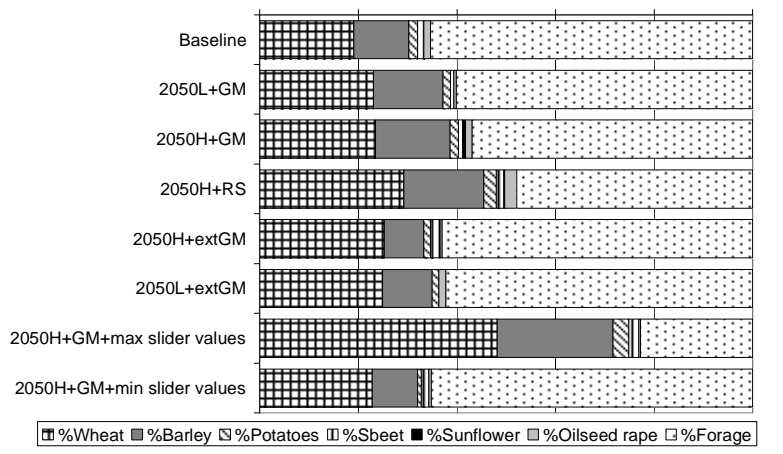

Sunflower $\square \%$ Oiseed rape $\square \%$ Forage

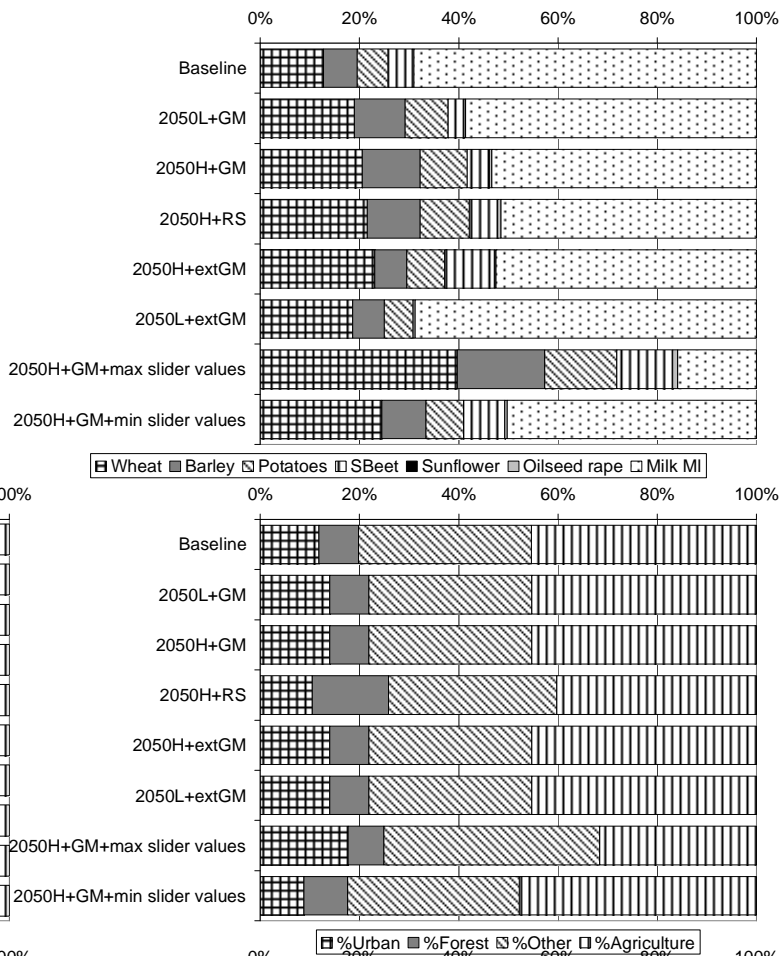

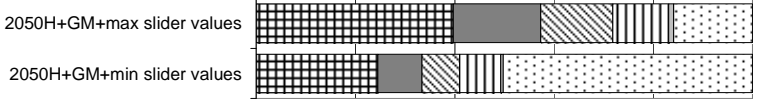

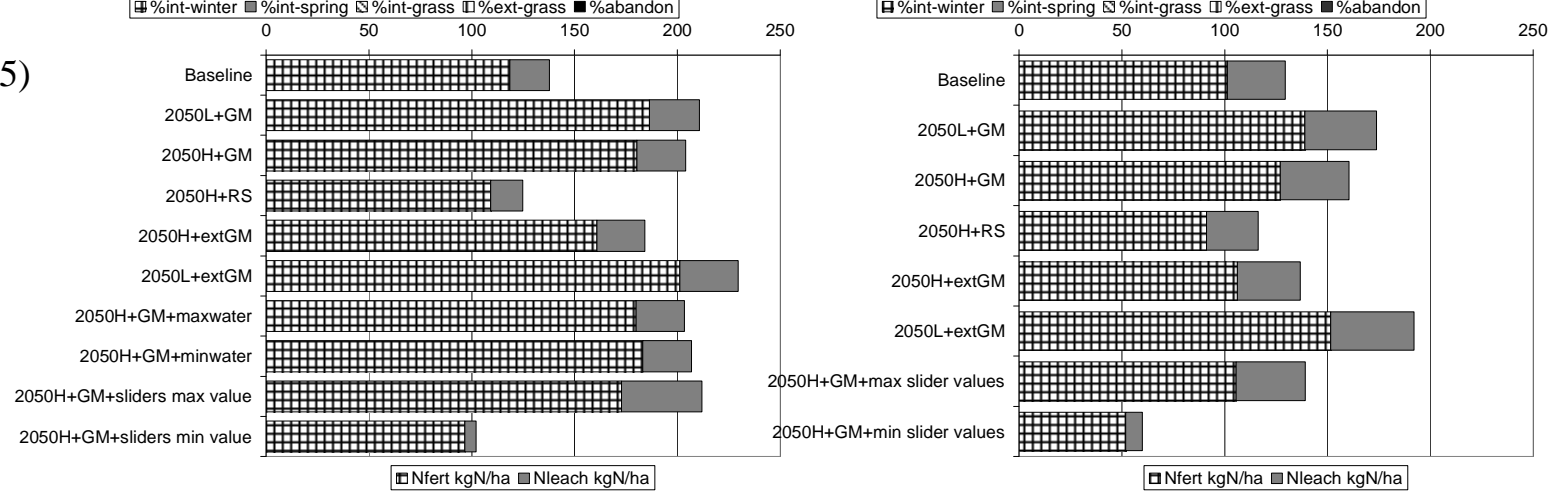

Figure 11 Effect of scenarios in the two regions on 1) \% of land area in each crop 2) \% of regional production of each type 3) \% regional land use 4) \% of each intensity of agricultural land use 5) Nitrogen 
use and leaching. The scenarios are a) baseline b) 2050Low (climate) +GlobalMarket (economics) c)

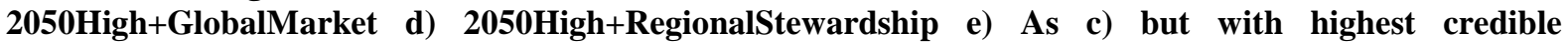
temperature and winter precipitation and lowest credible summer precipitation f) As b) but with lowest credible temperature and highest credible winter and summer precipitation g) As c) but with highest irrigation water available, $672 \mathrm{Ml} / \mathrm{d}$ (EAnglia only) h) As c) but with lowest irrigation water available, 168 Ml/d (EAnglia only) i) With all parameters at their highest setting j) With all parameters at their lowest setting 

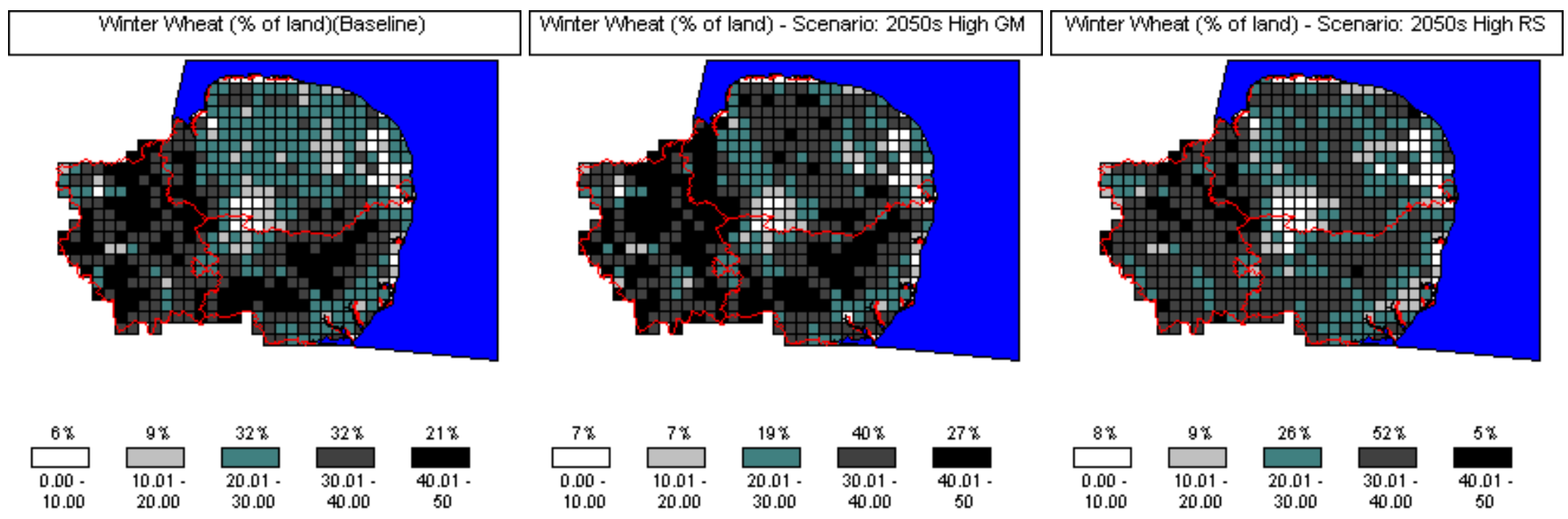

Figure 12 Comparison of 2050 High+GlobalMarket and 2050 High+RegionalStewardship scenarios with the baseline at a $5 \mathrm{~km}$ level in East Anglia - \% of grid area in winter wheat cropping ( $\%$ of all grids in each class) 


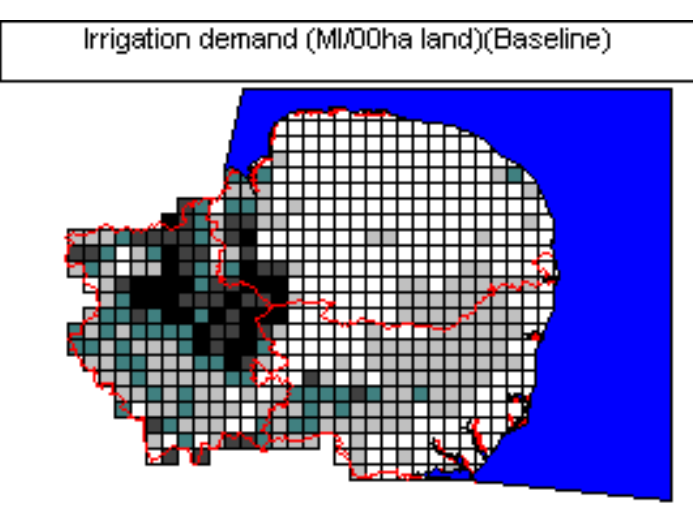

Irrigation demand (MMoha land) - Scenario: 2050s High GM

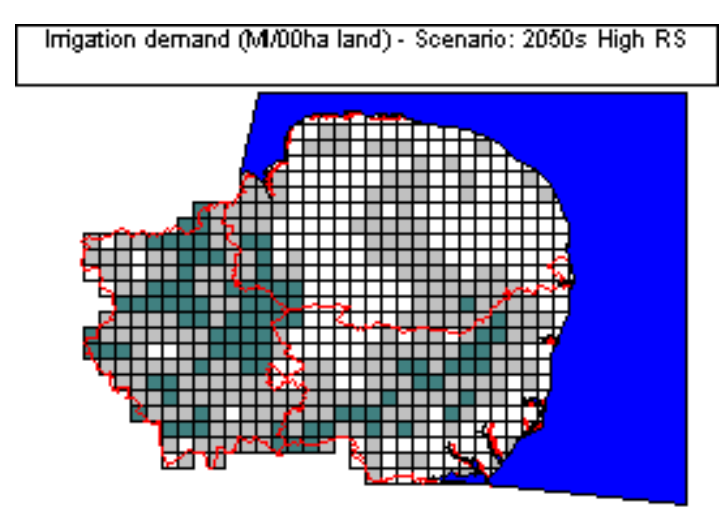

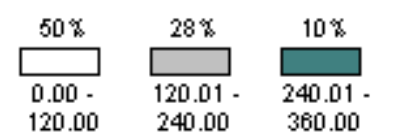

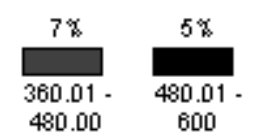

\begin{tabular}{|c|}
\hline $44 \%$ \\
\hline $0.00-$ \\
120.00
\end{tabular}

$\frac{27 \%}{\square} \frac{\square}{240.01}$

\begin{tabular}{r}
$24 \%$ \\
\hline 240.01 \\
360.00
\end{tabular}

\begin{tabular}{cc}
$5 \%$ & $0 \%$ \\
\hline $360.01-$ & $\begin{array}{c}480.01 \\
480.00\end{array}$ \\
600
\end{tabular}

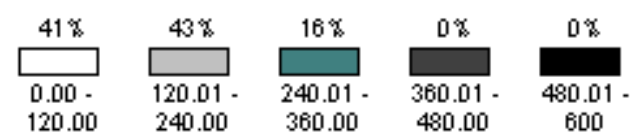

Figure 13 Comparison of 2050 High+GlobalMarket and 2050 High+RegionalStewardship scenarios with the baseline at a $5 \mathrm{~km}$ level in East Anglia - overall irrigation demand in each grid, litres/ha (\% of all grids in each class) 

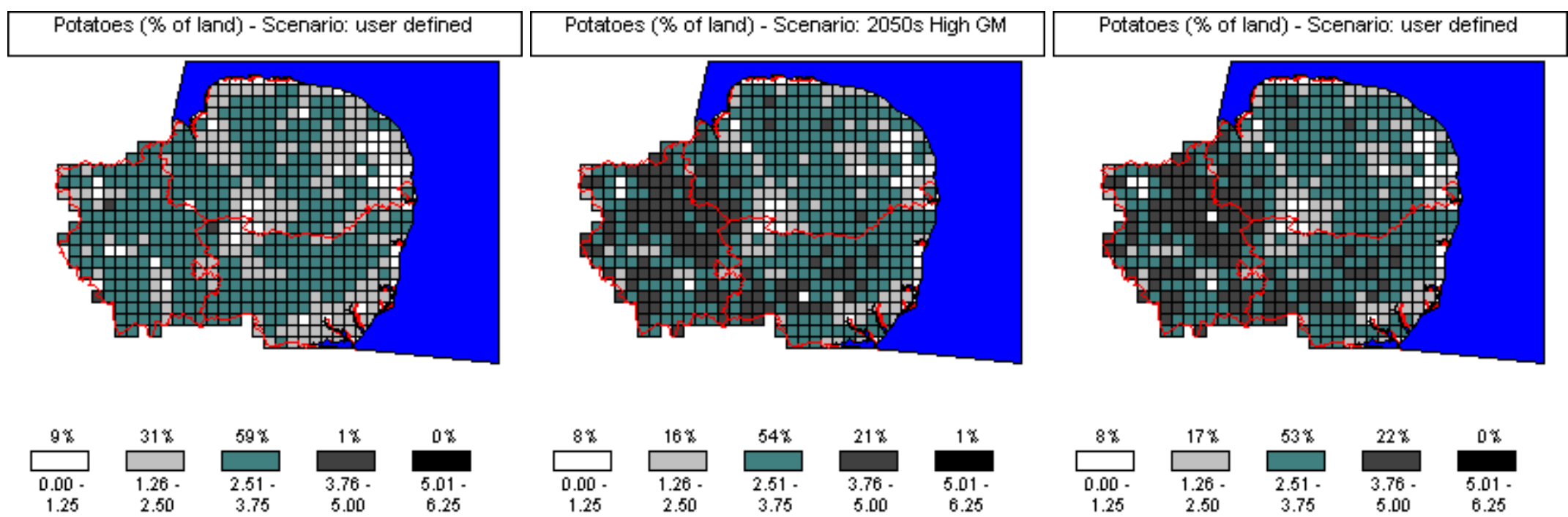

Figure 14 The effect of irrigation water availability on potatoes in East Anglia $(2050 \mathrm{H}+$ GlobalMarket $)($ Left=168, Middle= $420($ default $)$, Right $=672 \mathrm{MI} / \mathrm{d})-\%$ of grid area in potatoes (\% of all grids in each class) 


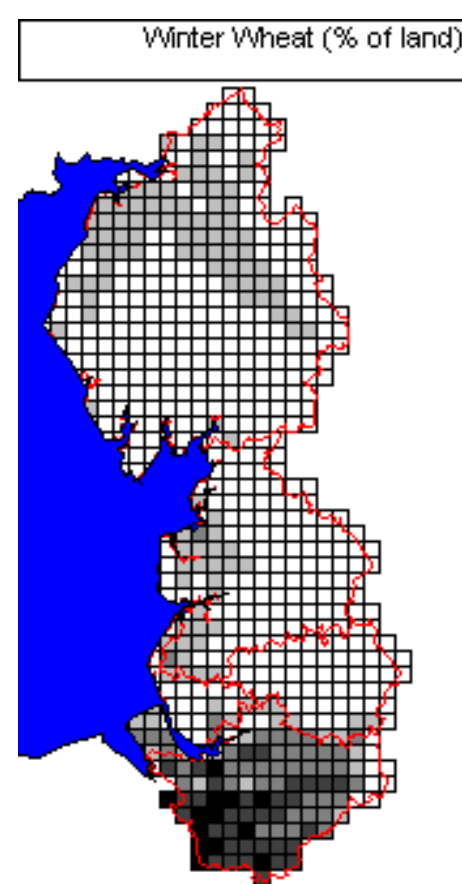

Figure 15 Comparison of 2050 Low+GlobalMarket and 2050 High+GlobalMarket scenarios with the baseline at a $5 \mathrm{~km}$ level in North West - \% of grid area in winter wheat cropping (\% of all grids in each class) 

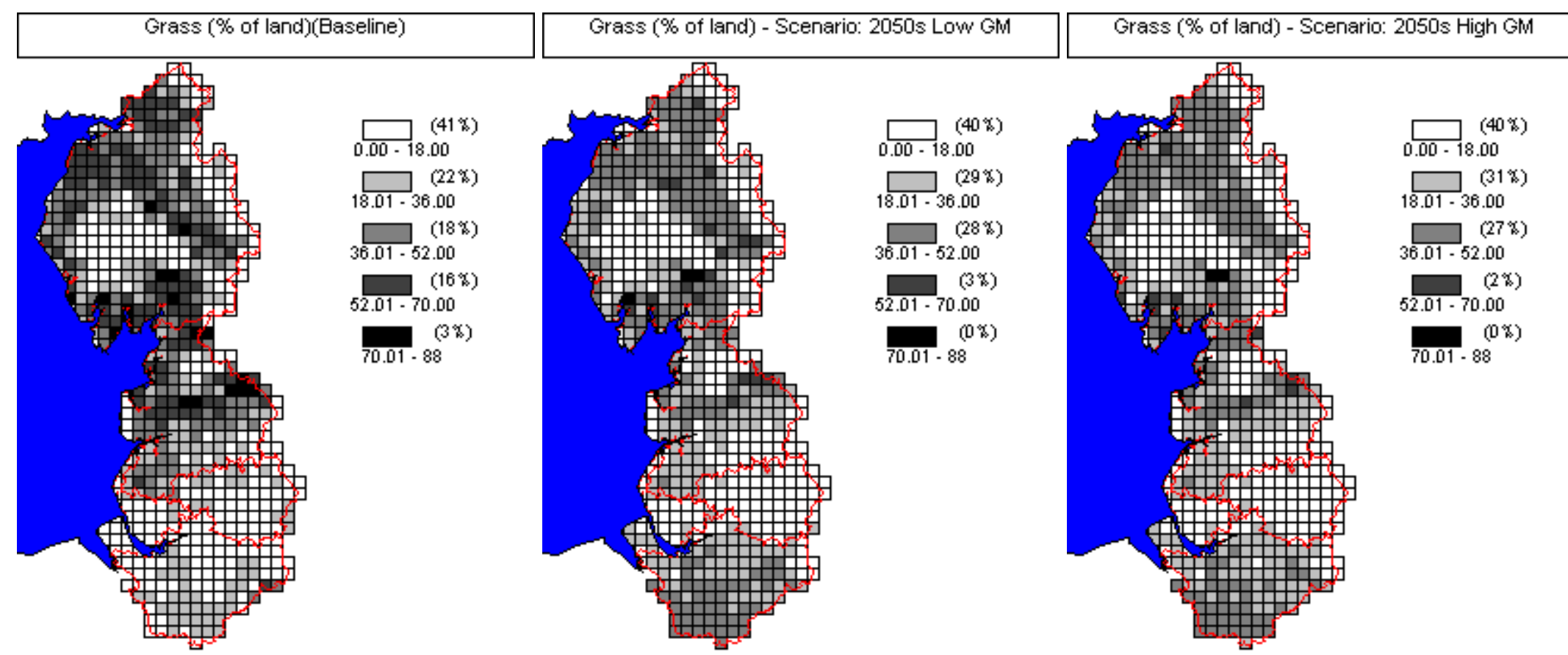

Figure 16 Comparison of 2050 Low+GlobalMarket and 2050 High+GlobalMarket scenarios with the baseline at a $5 \mathrm{~km}$ level in North West - \% of grid area in grassland ( $\%$ of all grids in each class) 
